Portland State University

PDXScholar

7-27-1973

\title{
Two Delivery System Contexts for the Elderly:The "Institutional" Approach and the "Community" Approach.
}

Mary Sarita Freer

Portland State University

Follow this and additional works at: https://pdxscholar.library.pdx.edu/open_access_etds

Part of the Family, Life Course, and Society Commons, Gerontology Commons, and the Medicine and Health Commons

Let us know how access to this document benefits you.

\section{Recommended Citation}

Freer, Mary Sarita, "Two Delivery System Contexts for the Elderly:The "Institutional" Approach and the "Community" Approach." (1973). Dissertations and Theses. Paper 1628.

https://doi.org/10.15760/etd.1627

This Thesis is brought to you for free and open access. It has been accepted for inclusion in Dissertations and Theses by an authorized administrator of PDXScholar. Please contact us if we can make this document more accessible: pdxscholar@pdx.edu. 
AN ABSTRACT OF THE THESIS OF Sister Mary Sarita Freer for the Master of Arts in Sociology presented July 27, 1973.

Title: Two Delivery System Contexts for the Elderly: The "Institutional" Approach and the "Community" Approach.

APPROVED BY MEMBERS OF THE THESIS COMMITTEE:

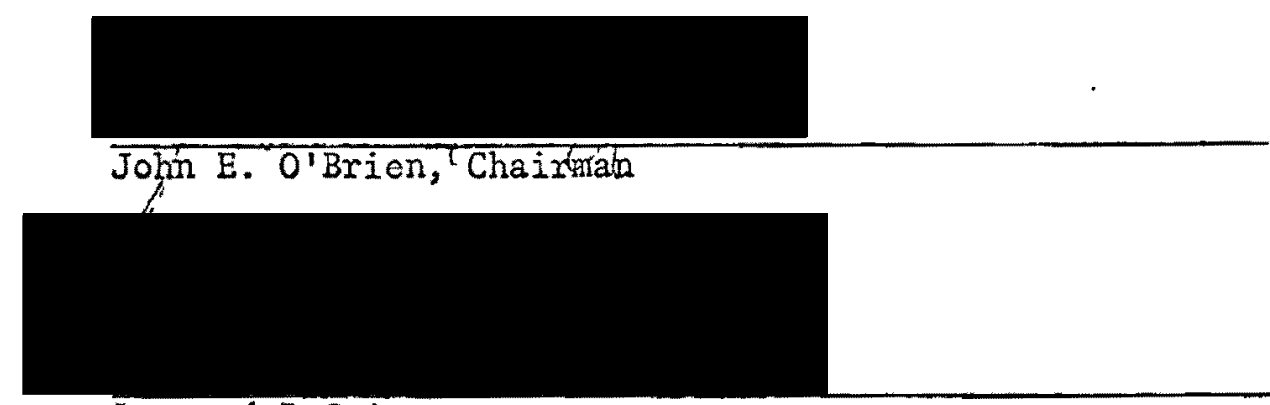

Leonard D Cain

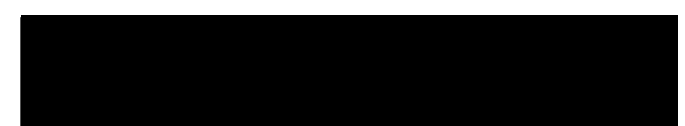

6. Barry Lébowitz

Theoretically every society has some institutional means which seeks to prevent and alleviate personal misfortune and illness. "Institutions are standardized solutions to collective problems." 1 The increasing population rate of older persons, many of whom suffer from chronic diseases and disabilities, does pose a collective problem for society. Formerly, the "institutional" approach developed to address the needs of ${ }^{1}$ Don Martindale, American Society (Princeton, N. J.: D. Van Nostrand
Co., 1960). 
chronic aging patients and society. Today the "community" approach, by which comnunity service agencies, whose goal is to help older adults remain independent of total institutional care by supplying supportive services, is achieving recognition.

This thesis is an exploratory study to assess similarities and/or dissimilarities between two distinct groups of elderly persons--those receiving services in a total institution and those living in the community but receiving supportive services via a community-based delivery/ system. This delivery system is concerned with supplying human services to those people assumed to be "at risk" of institutional care. It is assumed that the clients of such a system are similar to those persons within an institution.

The major purpose of this study is to validate this assumption. If this assumption is proved true, it is thought that it could have important consequences on future policies concerning health-care systems for the aged.

Residents of the two nursing home groups, one set from a private, sectarian home, and the other from a public home, were used to generate information on the institutional elderly. The comparative, non-institutionalized group consisted of aged persons living in the community but receiving varied services through an area wide community Project. Six services were offered by this Project: Outreach Counseling and Referral, Legal Aid, Geriatric Screening, Homemakers, Nutrition and Transportation. Careful analysis suggested that the aged residents in the nursing homes were not substantially more impaired than those served by the Project. On that basis it appears if there were a greater variety of alternative services available, many individuals who currently enter total 
institutions could quite feasibly remain as community residents.

One of the critical differences appeared to be that entrance into the nursing home was most often precipitated by an acute health trauna which resulted in entry into a general hospital. By implication, it appears that physicians and other medical professionals should be recruited into the on-going planning activities of commuity Projects, so as to increase the utility of community services to elderly hospital patients. Hence, in the event that complete recovery is not achieved by certain elderly patients within a reasonable period of hospitalization, medical personnel can call upon and recommend the utilization of community-based care services. Since these same elderly patients appear to have less contact with relatives and friends, and are more likely to live alone, and to be of foreign origin, such outside intervention and guidance seem essential.

Other recommendations include the encouragement that public policy be directed toward the development of a greater variety of community service alternatives, supported by federal and state funding, for elderly individuals whose self-maintenance is deficient. It seems that the usual definitions of suitable reimbursible treatment under health insurance and Medicare/Medicaid should be redefined to enable treatment from community and home service agencies to be delivered at low cost or no cost to the elderly who need them. A final recommendation urges the need for continued research into the different ways to deliver services to the aged, and to search continually for ways to answer the question, "How can one best provide services needed by older people?" 
TWO DELIVERY SYSTEM CONTEXTS FOR THE ELDERLY:

THE "INSTITUTIONAL" APPROACH AND THE

"COMMUNITY" APPROACH

by

SISTER MARY SARITA FREER

A thesis submitted in partial fulfillment of the requirements for the degree of

MASTER OF ARTS

in

SOCIOLOGY

Portland State University

1973 
TO THE OFFICE OF GRÁDUATE STUDIES AND RESEARCH:

The members of the Committee approve the thesis of

Sister Mary Sarita Freer presented July 27, 1973.
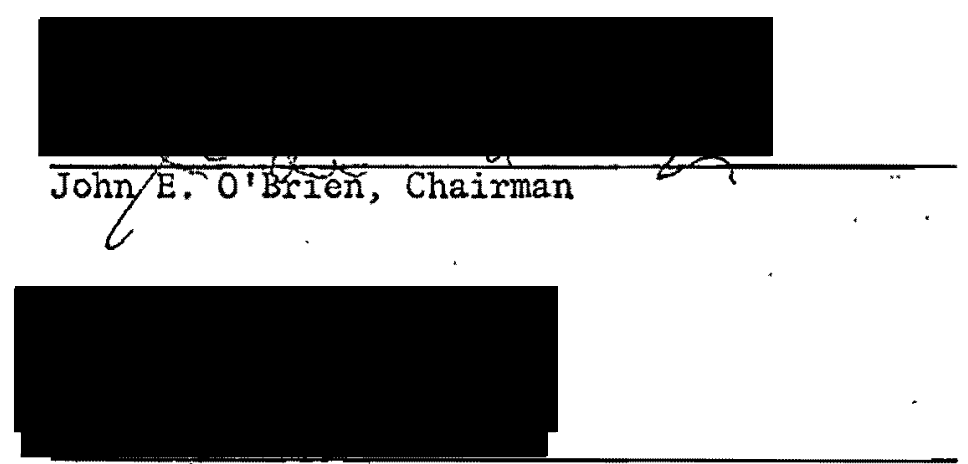

Leonard D Cain

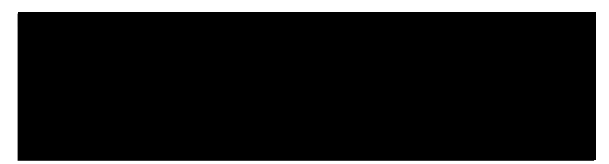

Barry /ebowitz

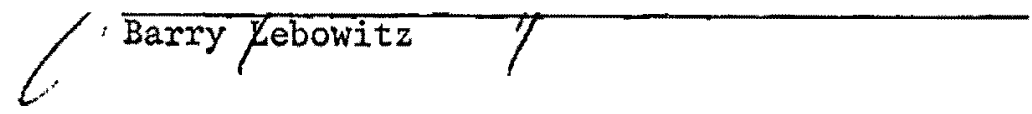

APPROVED:

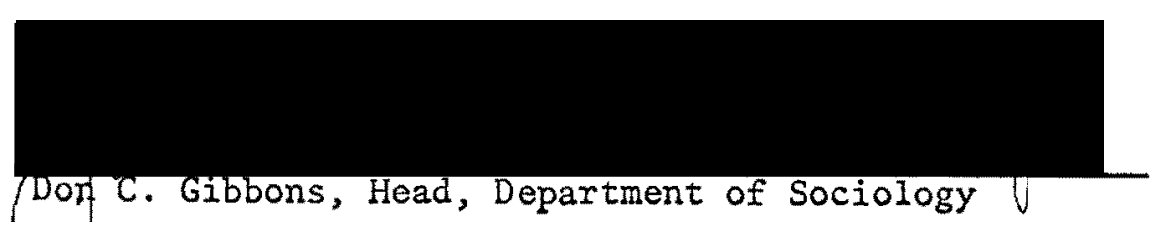

David T. Clark, Dean of Graduate Studies and Research 


\section{ACXNOWLEDGEMENTS}

I am indebted and deeply grateful to the Faculty, Staff and Students of the Institute on Aging for their encouragement, their sharing, and their interest in my work. Special thanks is given to the three Professors on my Thesis Committee, Dr. John E. O'Brien, Dr. Leonard Cain, and Dr. Barry Lebowitz, whose time, assistance and criticisms were much appreciated. Recognition and thanks is also given to Nancy Mancini, Linda Shoblad and Donna Lind for their invaluable assistance in data gathering and processing. Nancy Mancini, as Evaluation Specialist of Project ABLE, shared many insights used in this paper. Some of these insights are contained in an earlier technical report entitled, "Project ABLE Impact Analyses: Comparing Institutionalized Persons and ABLE Clients." This report was co-authored by Nancy Mancini and myself, under the direction of Dr. John E. O'Brien, and completed as a part of the evaluation component of Project ABLE.

Finally, special thanks and gratitude is given to my own Religious Sisters, the Sisters of Saint Francis of Philadelphia, whose love and support have constantly encouraged me in my educational endeavours.. 
TABLE OF CONTENTS

PAGE

ACKNOWLEDGEMENTS. . . . . . . . . . . . . . . . . iii

LIST OF TABLES. . . . . . . . . . . . . . . . . . vi vi

LIST OF FIGURES . . . . . . . . . . . . . . . . . . . $\mathrm{x}$

CHAPTER

I INTRODUCTION. .................. 1

The Aged: Description and Position in Society . . 1

Statement of the Purpose of the Study. . . . . . 4

Two Approaches in Caring for the E1der1y . . . . 7

The Community Approach

The Institutiona1 Approach

Sampling Theory and Procedure. . . . . . . 12

II METHODS EMPLOYED IN THE RESEARCH. . . . . . . . . 18

Overview of the Study. ............ 18

General Description of the Nursing Homes . . . 19

Description of the Project . . . . . . . 20

Data Collection. .............. 23

Method of Analysis............. . . 24

III A COMPARATIVE ANALYSIS OF THE INSTITUTIONALIZED AGED, AND THE AGED RECEIVING SERVICES THROUGH THE AREA COM-

MUNITY DELIVERY SYSTEM. . . . . ......... 25

Demographic Characteristics of the Elderly

Clients and the Nursing Home Residents . . . .. 25

Nativity

Age 
CHAPTER

PAGE

Sex

Marital Status

Education

Income

Living Arrangements and Housing. ...... 36

Social Contacts.............. . . . 43

Health Status............... 51

Physical Health

Mental Health

Summary Points of the Analysis. . . . . . . 58

IV RESEARCH AND THEORY IMPLICATIONS .......... 60

Discussion of Research Findings....... 60

Proposed Further Research . . . . . . . . 68

V POLICY RECOMMENDATIONS AND SPECULATIONS. . . . . . 71

REFERENCES . . . . . . . . . . . . . . . . . . . 77

BIBLIOGRAPHY . . . . . . . . . . . . . . . . 81

APPENDIX A . . . . . . . . . . . . . . . 85

Nursing Home Study

APPENDIX B . . . . . . . . . . . . . . . . 95

Needs Assessment Inventory

Current Social Service

Intake Form B 


\section{LIST OF TABLES}

\section{TABLE}

Ia A Comparison of Birthplace among Institutionalized Persons and the Project Clients ......... 26

Ib A Comparison of Birthplace between the Residents of the Two Nursing Homes ............... 27

IIa A Comparison of Sex Distribution among the Project Clients and Institutionalized Persons . . . . .

IIb A Comparison of Sex Distribution between Two Nursing Home Groups . . . . . . . . . . . . . 29

IIIa A Comparison of Current Married Status among Institutionalized Persons and the Project Clients. . . . 30

III A Comparison of Current Married Status between Residents of Two Nursing Homes. . . . . . . . . . 31

IVa A Comparison of Widowed Status among Institutiona1ized Persons and the Community Project C1ients. .

IVb A Comparison of Widowed Status between Residents of Two Nursing Homes .............. 32

Va A Comparison of Single, Separated or Divorced Marital Status among Institutionalized Persons and the Community Project Clients ........... 33

$\mathrm{Vb}$. A Comparison of Single, Separated or Divorced Marital Status between Two Nursing Home Groups. . . . . . . 34 
VI Percentage Distributions of the Three Populations

by Age Groups, by Sex, by Marital Status, and

by Nativity. . . . . . . . . . . . 34

VII Percentage Distribution of Two Groups by Education . . . 35

VIII Percentage Distributions of Three Populations by

Marital Status, Living Arrangements and Housing

Situation. ............... . . 39

IXa A Comparison of Living Alone among Institutionalized

and Non-Institutionalized Persons. . . . . . 40

IXb A Comparison of Living Alone between Residents of

Two Nursing Homes. . . . . . . . . . . 40

Xa A Comparison of Living with a Spouse among Institu-

tionalized Persons and the Project Clients . . . . 41

$\mathrm{Xb}$ A Comparison of Living with a Spouse between the

Residents of Two Nursing Homes . . . . . . . . 41

XIa A Comparison of Living with Others among the Com-

munity Project Clients and Institutionalized

Persons. . . . . . . . . . . . . 42

XIb A Comparison of Living with Others between the

Residents of Two Nursing Homes . . . . . . . . 43

XII Percentage Distribution of Three Populations in

Regard to Social Contacts with Children, Rela-

tives, and Friends............. . . 46 46

XIIIa A Comparison of Social Contact with Children among

Institutionalized Persons and the Project Clients. . 
XIIIb A Comparison of Social Contact with Children between Two Nursing Home Groups . . . . . . . . 48

XIVa A Comparison of Social Contacts with Relatives among Institutionalized Persons and Project Clients.................. 49

XIVb A Comparison of Social Contacts with Relatives between Two Nursing Home Groups ......... . 49

XVa A Comparison of Social Contacts with Friends among Institutionalized Persons and Clients ... 50

$\mathrm{XVb} \quad$ A Comparison of Social Contacts with Friends between Two Nursing Homes . . . . . . . . . 51

XVI Percentage Distributions of Three Populations with Regard to Physical Health, Hospitalization and Mobility. . . . . . . . . . . . . 53

XVIIa A Comparison of the Relationship of Chronic IIIness among the Project Clients and Institutionalized Persons...................... 54

XVIIb A Comparison of the Relationship of Chronic Illness between Two Nursing Home Groups . . . . . . . . 54

XVIIIa A Comparison of the Relationship of Mobility among Institutionalized Persons and the Community Project Clients............. 55

XVIIIb A Comparison of the Relationship of Mobility between Two Nursing Home Groups . . . . . . . . . 55 
XIXa A Comparison of the Relationship of Recent Hospitalization among Institutionalized Persons and the Project Clients. . . . . . . 56

XIXb A Comparison of the Relationship of Recent

Hospitalization between the Two Nursing Homes. . . 57 
LIST OF FIGURES

FIGURE

PAGE

1 Typology of Institutions. . . . . . . . . . . 15 
CHAPTER I

INTRODUCTION

\section{A. THE AGED: DESCRIPTION AND POSITION IN SOCIETY}

The purpose of this section is to examine in some detail attributes of the aged person, drawing upon the literature of gerontology. Human aging, a universal phenomenon, is often conceptualized and described in contexts of biological, psychological, and personality changes which develop within individuals over the life cycle. However, total comprehension of the aged requires insight and thought into their membership in society in the various social systems of which a society is composed. In reality, human beings grow, live, age, act, and react within kinship, neighborhood, community, economic, legal, and cultural systems of a society. 1

Numerous biological and psychological studies confirm that there is considerable variation in the chronological age at which individuals become "aged." However, when legislative and other policy-making bodies are faced with the necessity of isolating the aged as a special group, the line between aged and non-aged is frequently drawn at sixty-five years. However, this legal definition of "being old" is not a static boundary. ${ }^{2}$ Yet 65 years or older is the operationally defined category for the aged in this study.

Approximately one out of every ten Americans is sixty-five years of age or older. The older population is a large and rapidly growing 
segment of the total population and represents a mushrooming area of need for attention and resources. Assuming no radical changes in agespecific death rates, the 1970 level of twenty million older persons will grow to twenty-five million by 1985 and to twenty-eight million by the year $2000 .^{3}$

Besides these sheer statistical figures, the social position of the aged is of major interest. In many ways the aged are little different from their younger counterparts. They experience the ordinary human needs of food, shelter, social relationships, etc. Like all people, at times they need to call on resources outside themselves in order to meet some of these needs. It must be recognized that the passage of time is correlated, not only with certain physical and psychological changes, but also with changes in the social and economic setting of the individual. For the majority of Americans, the social situation of older persons and the condition of aging individuals result in losses of social roles, opportunities for socialization, family and friends, money, health, mobility, and independence. The cumulative effect of these losses tends to increase the frequency with which the individual must call upon resources outside himself, thus developing some degree of dependence upon others for the elementary needs of sustaining a meaningful life.

Currently in American society there is in process the quickening of interest and greater recognition of the special obligation to take care of the elderly person, when he can no longer effectively do so himself. However, the form of assuming responsibility is substantially different in concept from the former custodial pattern, symbolized by the "Home for the Aged." 
New considerations based on humane values and recognition of social and psychological needs are reflected in the approach which seeks the development of alternatives to institutional care, by providing a variety of supportive services.

The major goal of these [supportive] services is to provide specific assistance in those functions which the aged themselves are unable to perform adequately for themselves, thus supplementing the remaining strengths of the individual, in order that he may remain independent of the total assistance nursing homes or other institutional setting for as long as possible."

The opportunity to exercise independence and self-determination in all aspects of life for as long as possible is the philosophy underlying supportive services.

Abraham Kostick asserts that participation and choice are two important concepts in Post-Industrial societies, which must extend to the world of the aged. 5 older people are persons with individual feelings and with the right to be involved in decision-making on their own behalf. This same urgency for increasing the independence of the aged is echoed in the following words from the President's Council on Aging in 1963:

To most older Americans, a high degree of independence is almost as valuable as life itself. It is their touchstone for selfrespect and dignity. It is the measure they use to decide their importance to others. And $f$ it is their source of strength for helping those around them. 6

The 1971 White House Conference on Aging, through its policy recommendations and through the information developed from the grass roots conferences around the country, made it clear that much is needed to be done, if the great majority of older people are to maintain in their retirement years the standards of independence of their working years. 
B. STATEMENT OF THE PURPOSE OF THE STUDY

Along with the sheer numerical increase in population, and length- . ened life span, there also exists an increase in the prevalence of chronic, degenerate diseases, creating an immediate practical problem which demands attention and resources. Today, according to Goldfarb, approximately one million of the nearly 20 million elderly persons in the United States are now in institutions. 7 Unlike acute illnesses, the treatment of chronic diseases or disabilities requires long-term care, and often lifelong care, for the older person. The basic question to be answered is, "How does a society best provide services needed by older persons?"

With the decline of the extended family, which once provided protective care for the elderly, the institutional approach to care, via the Old Age Home and the Nursing Home, rose to have priority on the American scene. However, the ability of the modern family is questioned, as is the institutional approach, to care for the aged. The following viewpoints concerning the institutional approach clearly delineate the contradictory theoretical approaches which may arise when trying to balance the needs of the aged individual and the needs of the family and the community.

Talcott Parsons and Renee Fox strongly contend that the stability and harmony of the modern family are threatened by the presence in the home of old, sick, retarded, or handicapped family members. They suggest that the social organization of the modern, urban nuclear family makes it increasingly necessary, as well as convenient, for the family to surrender its traditional sick-care functions to a hospital (or perhaps in the case 
of the old a nursing home). ${ }^{8}$ However, a contradictory viewpoint is posited by Clark Edward Vincent. He argues that this "notion that the sick-care functions are incompatible with the organization if not the goals and interests of the modern family is contradictory to a number. of current trends." 9 Two of the trends he cites are the increased awareness of the potentially detrimental results of the patient's longterm separation from home and community life, and the increased use of family and community treatment settings. An examination of these two opinions leads to the conclusion that while Parsons and Fox are concerned with the needs of the family, Vincent's chief concern are the needs of the patient. As Odin Anderson and Ronald Anderson note in a footnote to the article, "Patterns of Use of Health Services," if the underlying assumptions of both Parsons and Fox and Vincent are correct, it appears that a basic dilemma may be present with the modern family unable to provide the support indicated by current trends in medical care. ${ }^{10}$ Therefore an attempt to explore and address the social relationships of the older person, whether he is at present receiving supportive care via an institution or via a community system, was thought important to help clarify both of the above viewpoints.

Presently in gerontological literature, and the trend in government policy and funding seem to be in the direction of the development of "alternatives" to institutional care for the elderly. This present approach is built on the theory that older people should be assisted in remaining independent of institutional care for as long as possible. However, this theory can only be put into practice through extensive programs of community care. 
Jerome Kaplan, the Editor of The Gerontologist, commenting on this current approach to seek alternatives to nursing home care, pointed out several assumptions underlying this procedure. These assumptions include:

1. There are alternatives.

2. Nursing Home care is the "last step."

3. Independent home care is "better" for the aged American than nursing home care.

4. People prefer to remain in their own homes under all conditions.

5. Home care is "cheaper" than nursing home care.

6. Many people do not have to be in nursing homes. 11

The major concern of the project under review was to investigate both the "institutional" and the "alternative" approaches in caring for the elderly, and to seek to clarify the above assumptions, through seeking insight into the following questions and areas of interest:

1. Is the Nursing Home a specialized facility, rendering a. necessary service to the aged?

2. Does there exist a great amount of pathology in the aged who seek institutional care?

3. Should institutional care be viewed as one needed program in a continuum of services for the elderly?

4. Is it possible that the individual components of a comprehensive service system do indeed permit community living as a realistic alternative to institutionalization?

5. Although the maintenance of independence is the philosophy behind a delivery system, is it possible that such a system might actually foster dependence even though it manifestly 12 seeks independence--by becoming a "wal1-less" institution?" 12

6. Is the population of elderly persons receiving services through community care systems similar or dissimilar to the formally institutionalized populations?

7. Does residence in a total institution seem to produce effects similar to, or dissimilar from, the reception of services via a community care system?

8. Does this study validate the following assertion of a Senate report:

There is reason to believe that millions of old people 
in our Nation today postpone treatment until the crisis stage simply because (1) they expect old age to bring physical infirmity and misery, and (2) gaps in Medicare and Medicaid coverage make it difficult for them to receive high-quality health services and supplies during and immediately after hospitalization. Thus, the over-reliance on hospital care, the most expensive level of care available is perpetuated and accentuated. 13

Answers to these questions are believed to contain significant policy implications concerning the health and care systems affecting the elderly. Ethel Shanas strongly suggested a decision by policy makers:

The choice before us seems straightforward: either we expand community health services to meet the needs of the elderly in the community--the bedfast, the housebound and those ambulatory with restrictions--or we need to begin a giant program of institution building to meet the needs of older Americans. 14

It was thought that this study would clarify some of the issues and facts surrounding such a "choice." Perhaps this choice is not as clearcut an issue as Shanas contends.

\section{TWO APPROACHES IN CARING FOR THE ELDERLY}

The Community Approach

For whatever reason, there has been a growing thrust as seen in the Iiterature, to provide alternatives to institutional care. But to date, very little data exist on

a. Whether it is "practically" achievable,

b. Whether it is economical, or

c. Whether such an approach is, in fact, moro "humano" for the elderly.

No literature as yet has appeared which compares an institutional population and a population of elderly persons receiving services through a community delivery system. However, the necessity for such delivery systems to meet the diverse needs of a heterogeneous aging population is 
becoming quite forceful in the literature.

It is the belief of Tobin, Hammerman, and Rector (1972) ${ }^{15}$ that one of the factors in American society responsible for the inadequacy of services to the aged is the emphasis given to institutional care. This, they reason, is due to the fact that the institutional care facility has become one of the most accessible sources of medical services for the aged persons in the lower and middle income and poverty groups. Kistin and Morris $(1972)^{16}$ believe that the lack of basic supportive services in the home and community account for much unnecessary institutionalization. Evidence, they assert, is growing to show that many. elderly and handicapped persons are placed in nursing homes and other institutions not for medical reasons but because essential services to assist in maintaining them in their homes and in their communities are lacking. The above statement seems well supported by the statistics from the Massachusetts Department of Public Health, which found that only $37 \%$ of the 100,000 patients in licensed nursing homes required fulltime nursing care. ${ }^{17}$ Thus Kostick (1972) ${ }^{18}$ urges individual communities to re-examine the structure for social services and to partialize services which an institution provides, and not to insist that individuals "purchase a complete package" of institutional life, when some service or services would suffice.

One reason that may contribute to the shortage of community-based supportive services is the nature of care which is reimbursable under "health" insurance plans, including those of Medicare and Medicaid.

The 1965 amendments to the Social Security Act initiated a significant and far-reaching change in the arrangements under which medical care was made available to millions of Americans. Medicare extended the 
social insurance program of O.A.S.D.H.I. to provide medical care to older citizens through the addition of Title XVIII to the Social Security Act. Medicaid was born with the enactment of Title XIX amendment to the same act. This amendment established a new federal program, which extended medical care to low-income groups irrespective of whether or not they were receiving public assistance. This amendment established national recognition of the fact that many Americans cannot afford necessary medical care--that many self-supporting but low-income families and individuals do not have sufficient monies to pay for medical and hospital care when illness strikes. ${ }^{18}$ This amendment was of special interest to the aged.

However, Medicare and Medicaid reimburse care only if it is rendered in an institution and/or is provided under physician's orders. Hence the institutional service market has grown in response to the economic demand, while the home service market has not. Hopefully, in the near future Medicare and Medicaid benefits will be extended to other forms of care. Pérhaps then the community service market will likewise expand. It should be noted that not all institutional care is reimbursible in an institutional environment-at least at present. Hopefully this too will change. As Section 1862(a) of the Social Security Act states:

Notwithstanding any other provisions of this title, no payment may be made under Part A or Part B for any expenses incurred for items or services--where such expenses are for custodial care. 19

Custodial care is defined in the following section:

Payment may not be made under title XVIII for the cost of inpatient services if the primary purpose is to provide custodial care; that is, care designed essentially to assist an individual to meet his activities of daily living. These are services which constitute personal care such as help in walking, and getting in and out of bed, assistance in bathing, dressing, feeding, and using the toilet, preparation of special diets, and super- 
vision of medication (including injections) which can usually be self-administered and which does not entail or require the continuing attention of trained medical or paramedical personnel. 20

It is obvious that many of the services which are non-reimbursible are the precise services needed by so many of the aged.

\section{The Institutional Approach}

The prevailing image of institutional life has largely been negative; the common belief is that most institutions have deleterious effects caused by the "dehumanizing" and "depersonalizing" characteristics of institutional environments. It is also a common assertion that the aged in institutions constitute a relatively disadvantaged group in regard to health, social ties, and economic resources. 21

A survey of the literature, comparing institutional and non-institutional samples of people, does indeed seem to suggest that the institutionalized person does have an impaired level of over-all adjustment, a reduced capacity for independent thought and action, depressive mood tone, low self-esteem, and other negative attributes.

$\mathrm{Pan}^{22}$ reported that institutionalized persons suffer from the following disadvantages: fewer contacts with friends, poorer quality of familial relationships; less opportunity for group activities; lower satisfaction in life; and poorer attitudes towards health, leisure, happiness and usefulness, as compared to non-institutionalized persons. Laverty ${ }^{23}$ concluded that mental and physical deterioration may be retarded by encouraging normal community living as opposed to premature institutional admission. Pollack, Karp, Kahn and Goldfarb ${ }^{24}$ found that selfderogatory responses to their own image was of higher incidence in the institutionalized group rather than in a non-institutionalized group. 
Bennet and Nahemov's study of $1965^{25}$ directed attention to the depersonalizing effects of institutionalization upon the aged, while the study which $\mathrm{Coe}^{26}$ conducted during the same year suggested that, due to. the lessening of contribution to the social system, the institutionalized aged individual may show a depreciation of self and loss of personal identity. Several negative terms have been used to portray the different socio-psychological effects of living in institutions, such as "mortification of self" (Goffman, 1961), "hospitalism" (Spitz, 1945), "depersonalization" (Townshend, 1962), and "regressive pattern to infantile reactions" (Laverty, 1950).

Thus the general thrust of the above research posits that institutional environments may indeed have negative effects upon the individual. However, there have been some research studies which indicate that significant proportions of elderly residents of institutions do not in fact differ physically or mentally from their community counterparts. A study by Gitlitz which assessed morbidity, mortality, and psychiatric disordex rates, found that the institutionalized residents did not differ from those of the aged in his study living in the community. ${ }^{27}$ Anderson, studying the impact of institutionalization on the aged, did not find that the nursing home residents had impaired self concepts. ${ }^{28}$ In fact, according to Anderson, instead of institutionalization, it was variation in amount and quality of interaction that was found to explain changes in self-esteem. It was also proposed that institutionalization of ambulatory older persons often increases the quantity and quality of interaction and therefore raises self-esteem. Another study by Lieberman, Prock and Tobin (1958), comparing community residents of such homes, failed to show personality characteristics or occurrence of crisis events 
distinguishing those who entered institutions from those who remained in the community. They also concluded from this study that "effects that have been frequently ascribed to institutional living are reported as aspects of the waiting period, implying that these psychological qualities may articulate more to the symbolic meanings and fantasies surrounding institutions than to the critical experience of institutional Iife. ${ }^{29}$

Viewing the contradictory results of the research studies, it is evident that in actuality there seems to be little clear evidence of the precise effects of institutional living, that is, which facets of institutional living prove detrimental and which facets prove beneficial, to which types of residents. Shanas' study of 1961,30 based on survey data, suggests that the majority of institutionalized aged have real. needs they are attempting to solve via the institution. However, clarification of needs and identification of what type of person would benefit from an institution is, still lacking.

\section{SAMPLING THEORY AND PROCEDURE}

Every society has some institutional means which seeks to prevent and alleviate personal misfortune and illness. According to Don Martindale, "Institutions are standardized solutions to collective problems." ${ }^{31}$ Historically nursing homes are based on the philosophical tradition of the "poor-house" which was a humanitarian societal attempt to cope with permanent disabilities due to chronic diseases and financial stress by providing shelter and comfort.

However, the nursing home, while a social system in itself, is also intricately involved with the world beyond its walls. Today such changes 
in the technology of health care as the increased recognition of, and a greater emphasis on, the social, psychological, and economic needs of the clients must necessarily lead to a changing view of institutional care.

Joyce Hertzler's definition of a social institution stresses the two facets which must be considered--the individual need and the social need. The greatest harmony and "success" of any institution occurs when congruence exists between the individual needs and societal needs.

Social institutions are purposive, regulatory, and consequently primary cultural configurations formed, unconsciously and/or deliberately, to satisfy individual wants and social needs bound up with the efficient operation of any plurality of persons. 32

A growing recognition that the institutional environment may not be the most successful health care system to meet either the needs of the individual aged person or be the most efficient and economical method for society is indeed evident in gerontological literature. Rather what is being stressed in the literature is a community supportive system offering a variety of agencies in the community, which will be of assistance in meeting the needs of the aged--financial, social and medical. In fact, the personal social services which are now coming to the fore are large-scale experiments in helping those in need, and also are attempts to bring greater synchronization between the two perspectives--the individual and the society.

Institutional care and community care of the aged are interrelated. Both are facets of the same cultural definition by which society deals with the aged and renders services to them. Both reflect the attitudes and values of society. According to Martindale's definition of an "institution," both methods of care are forms of "institutions," each 
responding to an area of need. Institutional care can be viewed as a vital community service. However, it is speculated that many persons are misplaced in regard to institutional care. As reported to the Special Comnittee on Aging, United States Senate, October 1971:

Studies of the characteristics and needs of nursing home populations indicate that 15 - 20 percent of such persons are absolutely misplaced in the institutional environment. Their residence in such settings is directly associated with the absence of intermittent services and flexibly applied home care supports to daily living in the neighborhoods from which they came. 33

Health care was thus conceptualized as one response to a societal need and was envisioned as a continuum ranging from no direct personal health intervention to total intervention. The least intervention would be for those aged living in the community. Here no specific intervention would be present, other than general societal health preventive measures, (e.g., fluoridation in water), and possibly financial aid in the form of pensions. Total institutional care could be conceptualized as the highest level of intervention affecting not only the physical sphere but also the environmental sphere, which may affect the social and mental aspects of life.

Due to the changing technology of health care, and the controversy over misplacement of individuals receiving services through different forms of care, the two forms of care chosen for this study were the "total institutional" environment, and the community-based delivery system. Both these forms were viewed as differing in degree of intervention on the continuum of health care.

Erving Goffman's definition of a total institution, with its four major aspects, was adopted as a base-line for specifying the dimensions along which the populations could be situated. Goffman's four major 
aspects include:

First, all the aspects of life are conducted in the same place and under the same authority. Second, each phase of the member's activity is carried on in the immediate company of a large batch of others, all of whom are treated alike and required to do the same things together. Third are the phases of the day's activities which are tightly scheduled, with one activity leading at a pre-arranged time into the next, the whole sequence of activities being imposed from above by a system of explicit formal rulings and a body of officials. Finally, the various enforced activities are brought together into a single rational plan purportedly designed to fulfill the official aims of the institution. 34

Dimensionalizing the concept "institutionalization" along a single continuum, the following typology was constructed:

Figure 1: Typology of Institutions

\begin{tabular}{|c|c|c|c|c|}
\hline & $\begin{array}{l}\text { ALL ASPECTS } \\
\text { OF LIFE } \\
\text { CONTROLLED }\end{array}$ & $\begin{array}{c}\text { BATCH } \\
\text { PROCESSES }\end{array}$ & SCHEDULING & $\begin{array}{l}\text { RATIONAL } \\
\text { PLAN }\end{array}$ \\
\hline $\begin{array}{l}\text { TOTAL } \\
\text { INSTITUTION }\end{array}$ & YES & YES & YES & YES \\
\hline $\begin{array}{l}\text { HALFWAY } \\
\text { HOUSE }\end{array}$ & No & YES & YES & YES \\
\hline $\begin{array}{l}\text { COMMUNITY.- } \\
\text { BASED } \\
\text { DELIVERY } \\
\text { SYSTEM }\end{array}$ & NO & NO & YES & YES \\
\hline $\begin{array}{l}\text { AFFILIATE } \\
\text { PROGRAM }\end{array}$ & No & NO & NO & YES \\
\hline "COMMUNITY" & NO & NO & No & No \\
\hline
\end{tabular}

The "total" institution is a social system with two separate but interrelated systems, a staff system and a resident system. Such an insti- 
tution has its own traditions and norms to which all individuals are expected to adjust. Often the most minute behaviors are scrutinized and regulated, not only by the staff members but also by the other residents. In Goffman's terminology; the residents are "leveled" so that many of their previous social characteristics and experiences are irrelevant to the congregate living style of the institution. "Batch processes" include the concept that programs and daily activities are often designed and imposed by the administration with little chance for individual personal decisions. The official aim of a total institution such as a. nursing home is to provide nursing care for the aged, chronically ill and convalescent patients. The scheduling of such programs as nursing care, medical care, physical therapy, occupational therapy, meals, shelter, and the daily routine of activities are designed in the most efficient manner possible to attain their over-all aim.

The halfway house shares many aspects of the "total" institution, with the exception that not all aspects of life are controlled. It also implies more of a temporary institutionalization. There is leeway for individual initiative and responsibility and personal decision-making. The community-based delivery system shares in the aspects of scheduling and rational planning with the "total" institution. However, the unit of interest is the individual, not a "batch process." The primary objective of this type of system is to deal with the major problems which threaten the independent living of older adults. The affiliate program is an organization which meets a certain need or philosophy of the individual or organization. A "loose" structure is usually maintained. A comprehensive medical plan would be a typical example. A "community" group shares in none of the four aspects. The aged in the 
"community" can be viewed as individuals who are free agents, remaining their own responsibility as far as daily activities are concerned. It is from the "community" that the recipients of the community-based. delivery system were drawn.

With the construction of such a typology, the populations chosen for this study fall into two distinct categories. Those in the two nursing homes live in "total" institutions, the others in a communitybased delivery system. The two nursing home populations share in all four aspects of the "total" institution. However, each of the homes varies in the intensity of degree of each aspect. This difference will be considered in the analysis of data. 


\section{CHAPTER II}

\section{METHODS EMPLOYED IN THE RESEARCH}

The research design was projected to be more exploratory than definitive, more hypothesis generating than hypothesis testing. A number of methodological difficulties are evident, which, in fact, limited the use of statistical techniques. This was due to the fact that comparable data were not always available for the Project clients and the two institutionalized groups. Therefore, inferential comparisons were sometimes substituted for exact ones. I will attempt to explicate these comparisons and resolve them as best $I$ can. Thus, the research reported is only a beginning of that which needs to be done, and is to be viewed in that context.

\section{A. OVERVIEW OF THE STUDY}

This exploratory study was concerned with two distinct groups of elderly persons--one which received services in a total institutional environment and one which lived in the community but received supportive services via a community-based service delivery system. Two nursing home groups; one from a private non-profit, sectarian home and the other from a public home, were used to generate information on the institutionalized elderly. Both nursing homes are situated in the Portland metropolitan area.

The comparative non-institutionalized group consisted of aged living in the community but receiving varied services through a community area- 
wide Project. This Project was one of the original Model Projects supported by funds from the Administration on Aging, Social Rehabilitation Services, Health, Education and Welfare. Six services were offered under the Project: Outreach Counseling and Referral, Legal Aid, Geriatric Screening, Homemakers, Nutrition, and Transportation.

It was the aim of this study to search out and seek to understand better the consequences of residence in a total institution for well being of the elderly; to see if, and to what extent, the existence of a community care system is producing similar or dissimilar effects and if they are catering to a similar population of elderly persons. It was thought that answers to some or all of these questions would be important to future policies concerning health care systems for the aged.

\section{B. GENERAL DESCRIPTION OF THE NURSING HOMES*}

The McGill Nursing Home is a non-profit Catholic health care facility, which has been in operation since 1963. Architecturally its modern design would be considered an "enlightened" structure. Its administration too was somewhat "enlightened." The residents of this facility were encouraged by the staff and administration to be independent in much of their planning for the day. Encouragement was given to develop skills through occupational therapy and continued education and opportunities were offered by the establishment of a library and music center. A "noninstitutional" pattern of relationships and activities inside and outside of the home was fostered and encouraged. The residents are free to visit and stay with relatives and friends outside of the institution. Although homes.

*The names McGill Home and Columbia Home are pseudonyms for the two 
the vast majority of the residents are admitted for medical reasons, the patient population is a heterogeneous group. Individual needs ranged from total skilled nursing care to the desire for independent living in a protected environment. This home catered to the middle and upper socio-economic classes. The majority of the patients were financially maintained by their families or by their own trust funds. The rates of the Home, effective as of January 1, 1972, include:

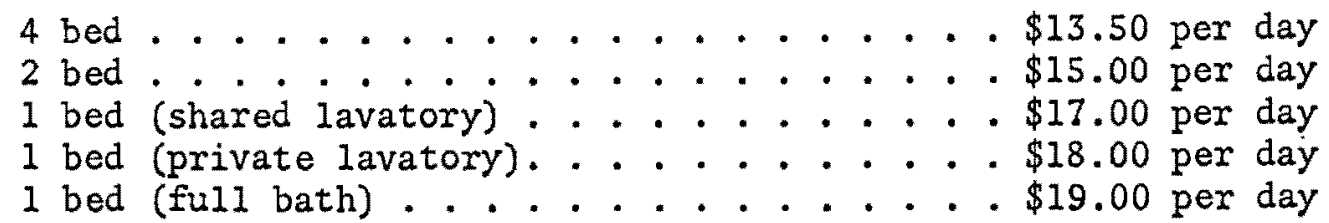

Only $15 \%$ of the 110 patients received welfare payments, and an additional $6 \%$ received Medicare payments.

The second Nursing Home, Columbia, was a County Home with a resident capacity of 300 patients. The needs of the aged varied from skilled nursing care to custodial care. The majority of the residents of this Home were financially maintained by Welfare and Medicare payments. For privately financed patients, the rates average $\$ 7.00$ per day for custodial care and $\$ 12.50$ per day for those patients needing partial or complete nursing care.

\section{DESCRIPTION OF THE PROJECT}

The Project, which supplies the sample for the non-institutionalized population, was one of the original Area Wide Model Projects supported by funds from the Administration on Aging, Social Rehabilitation Services, 
Health, Education and Welfare.* The Project addresses itself to the problem of limited alternatives to institutional care and to the lack of adequate services which could prevent or delay physical and mental dysfunction.

The primary objective of the Project has been to develop a comprehensive service system which has the capacity to deal with the major problems which threaten the ability for independent living of older adults.

The availability of specialized social services is viewed as important to an aging population. The major goal of these supportive services is to provide specific assistance. in those functions which the aged themselves are unable to perform adequately, thus supplementing the remaining strengths of the individual in order that they may remain independent of the total institution for as long as possible.

Six services were contracted under the Project. Those services include Outreach Counseling and Referral, Legal Aid, Geriatric Screening, Homemakers, Nutrition, and Transportation. Counseling and Referral was an outreach service designed to search out older adults who needed assistance to maintain independent living, to counsel with them about their needs, to refer them to appropriate services, to serve as advocates

*This Project is Project ABLE: A Better Life For The Elderly; an Area Wide Model Project supported, in part, by funds from Title III, the older Americans Act, Administration of Aging, Department of Health, Education and Welfare. The Project was developed in Multnomah County, Oregon, under the direction of the Oregon State Program on Aging, with Mrs. Marion Hughes as Coordinator. The service components of the Project are operated in Multnomah County, and the city of Portland, Oregon, under the guidance of the City-County Commission on Aging, with Mr. 0. J. Gates as Director. The Project is coordinated by Mr. Roger N. 01son, and Chairman of the Board is Mr. Samuel Lissitz. Portland State University's Institute on Aging; under the direction of Dr. John E. O'Brien, is contracted for monitoring and evaluation. 
on their behalf, and to follow up to assure that needed services have been provided. This component was directed from an existing information and referral service for older adults although the outreach counselors were stationed in four neighborhood sites geographically distributed in the county.

Legal Services involves the use of an attorney assigned to and working for the Project who could protect the interests of older adults in the Project, represent them in legal matters, serve as consultant to service workers in the Project, train Outreach Counselors in advocacy, and collect data that could be used to effect reform in law and procedures that tended to threaten the independence of older adults.

Geriatric Screening provides a Geriatric Screening Coordinator in the County Department of Medical Services to coordinate the agency's resources to assist the most frail and disabled elderly group; to utilize Public Health Nurses; and to strengthen the social work, medical, psychiatric, legal, and other resources needed to deliver surrogate and supportive services.

Homemaker Services involves a team of homemakers, a supervisor, and a social worker to provide case planning, housekeeping and personal care for older people who need help to remain in their own homes.

The Nutrition component delivers meals to the homes of older adults who are unable to cook for themselves or to get out to meals and to provide, additionally, human contact and some nutrition education.* 1971

*Project overview abstracted from the Project proposal, December 21, 


\section{DATA COLLECTION}

Data from the two Nursing Homes and the Project have been collected as part of the evaluation component of the Project, and are stored in the Institute on Aging, Portland State University.

The Information received from the first Nursing Home was based on the method of questionnaire and personal interview, and also from personal history and medical reports. The questionnaire was administered to those patients who had lived in this Nursing Home no longer than two years, and who were at least 65 years of age. This group also had the added restriction that the patients being interviewed could not have entered this Home directly from another one. This criterion was chosen to maximize the effects of this most recent institutional experience. It was thought that by limiting the time span it would increase the likelihood that the residents would be more cognizant of pre-institutional experiences, and more "in touch" with those events and circumstances leading to their institutionalization. The information received from the second Nursing Home was based on personal history and medical records of patients with similar restrictions of age, duration of stay, and entrance from another Nursing Home.

The data on the Project population were obtained from the Project intake and needs assessment records. Intake data are recorded on all persons referred to the Project services as well as on those persons not referred but who did receive substantial counseling from the intake or outreach staff. The intake records include a demographic form and a needs and condition inventory. Information on all the individual's housing, health, social contacts and economic status, and his or her needs 
for service are noted. The data for this study were obtained from intake records completed during the first six months of the Project: May through October, 1972. There were 1,404 intake forms and 787 needs assessment inventories processed during this time.

\section{E. METHOD OF ANALYSIS}

Each of the Nursing Home groups will be compared to the clients of the community delivery system, using percentages. It is believed that by comparing percentages it is possible to get a very good indication of the degree of relationship between two variables. Variables that appeared to be important in distinguishing the non-institutionalized group from the institutionalized group were examined more closely. The Chi-Square test of independence was used. This test was chosen first to establish the existence of a relationship between two variables. Yule's Q measure was also calculated for each relationship. This measure was chosen to indicate the strength or degree of relationship. This added measure of strength was thought important, since in actual fact, a significant level does depend on two factors: the strength or degree of relationship and the size of the samples. Since the Project population was large, it was possible that a relationship might appear significant, and in reality be a very weak relationship with a large sample.

The data will be looked at under four main categories: The Demographic Characteristics of Elderly, Clients and Nursing Home Residents; Living Arrangements and Housing; Social Relationships with Children, Relatives and Friends; and Health Status, which includes both mental and physical health. 
CHAPTER III

A COMPARATIVE ANALYSIS OF THE INSTITUTIONALIZED AGED, AND THE AGED RECEIVING SERVICES THROUGH THE

AREA COMMUNITY DELIVERY SYSTEM

\section{A. DEMOGRAPHIC CHARACTERISTICS OF THE ELDERLY CLIENTS AND THE NURSING HOME RESIDENTS}

Nativity

In contrast to the general population of all ages, the older adult is more likely to be foreign-born. Data on both the nursing home populations and the clients of the Project revealed that the majority of all three samples were American-born Caucasians. However, among the institutionalized groups there is a noticeably higher percentage of foreignborn residents.

Ninety-six percent of the elderly reached by the Project were Caucasian, with $91 \%$ being American born. Twenty-nine percent were born in the Northwest and a noticeable $50 \%$ were born in the Midwestern States. A similar distribution, with the exception of the higher incidence of foreign-born residents, was evident in both nursing homes. At McGill, 94\% were Caucasian, $75 \%$ were American born, $29 \%$ were born in the Northwest, and $32 \%$ were born in the Midwestern States. At Columbia, $75 \%$ were born in the United States, with $96^{\circ}$ being Caucasian. Thirteen percent of this group claimed the Northwest as their birthplace and $34 \%$ the Midwestern States.

Birthplace was analyzed more closely. The two categories imposed were foreign-born and born in the United States. From the data, it 
appeared that place of birth and health care delivery system are not independent of one another. Project clients and each nursing home were compared separately, in case differences between nursing homes, and not between institutionalized and the community group, were reported, as seen from the following tables.

\section{TABLE Ia}

A COMPARISON OF BIRTHPLACE AMONG INSTITUTIONALIZED PERSONS AND THE PROJECT CLIENTS

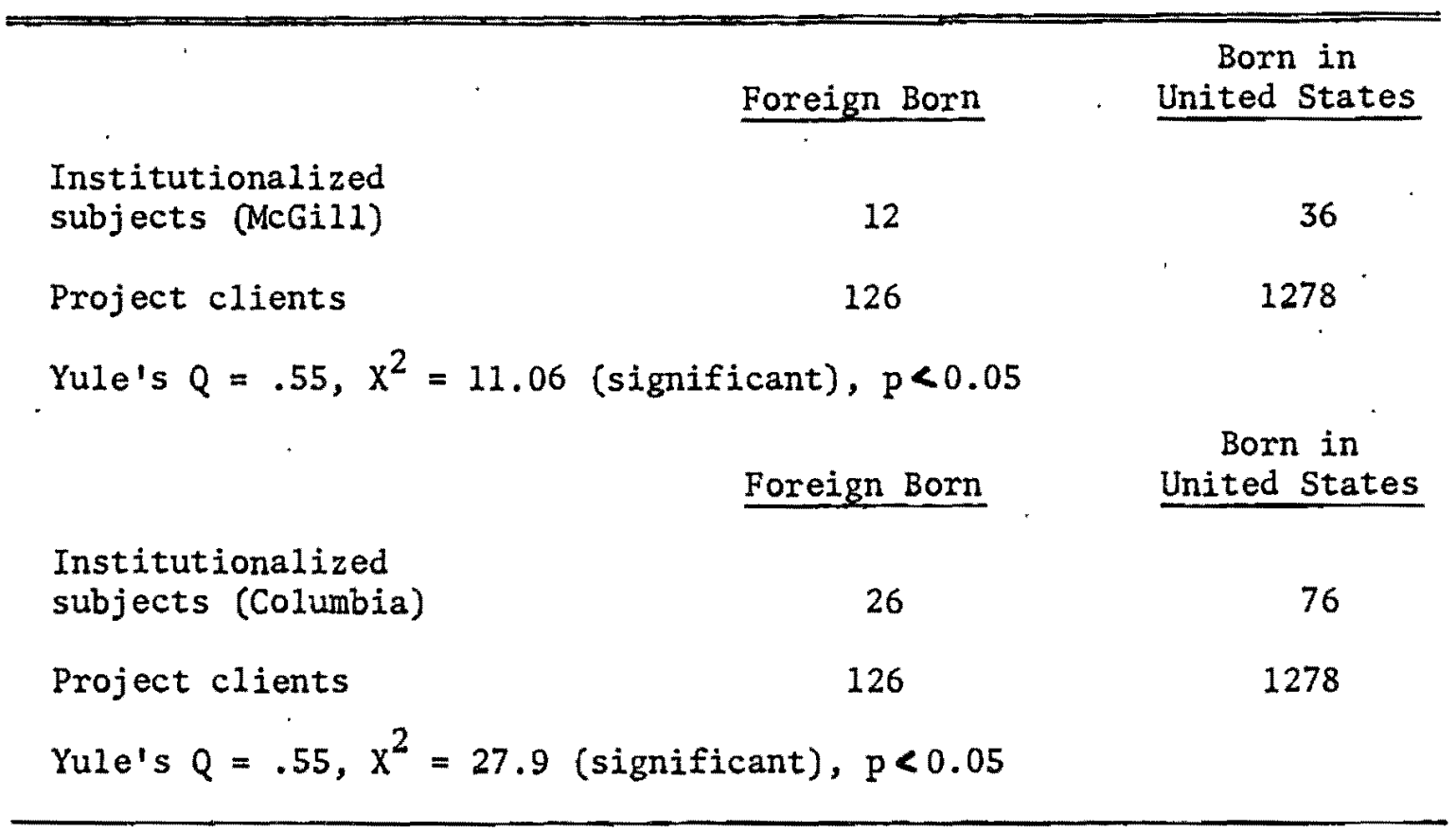

As a further check that significant noted differences were due to the difference between the community delivery service and not a difference between the two nursing homes, both nursing homes were also measured on the same variables. 
TABLE Ib

A COMPARISON OF BIRTHPLACE BETWEEN THE RESIDENTS OF THE TWO NURSING HOMES

\begin{tabular}{|c|c|c|}
\hline & Foreign Born & $\begin{array}{c}\text { Born in } \\
\text { United States }\end{array}$ \\
\hline McGill Residents & 12 & 36 \\
\hline Columbia Residents & 26 & 76 \\
\hline
\end{tabular}

From the above results, it can be noted that in these two institutionalized groups, when compared to a "community" group, birthplace is a significant factor. Besides establishing a relationship, Yule's Q was also calculated to give some indication of the strength of the relationship. This measure is noted just below the table.

$\underline{\text { Age }}$

The older elderly person was reached by both the institutionalized facilities and by the community-service system. The Project specifically emphasized reaching persons at least 65 with the highest priority for services being given to persons 75 years and older. This emphasis is reflected in the data from the first six months of operation. of the 1,404 older adults 10 cated during this period, $18 \%$ were under $65,31 \%$ were $65-74$, and $57 \%$ were 75 or older. In fact, 217 persons had reached 85 years of age. The median age of the Project population was 76 years of age. Comparing these figures with the populations of the two nursing homes showed that there are not substantial differences: At McGill, the median was 80 and at Columbia it was 72 . . 
Sex

Both the Project and the McGill Home served more females than males. Although the Project was not designed to focus on women more than men, it was expected that females would make up the majority of clients, since they outnumber males over the age of 55 . This expectation proved accurate as $73 \%$ of the clients were women. McGill also had a higher proportion of females with $77 \%$ female to $23 \%$ male. However, Columbia had a higher percentage of males, $71 \%$, as compared to $29 \%$ females. This surprisingly high distribution of males is due in part to the fact that many residents of this home are members of the county's transient and Skid Row populations who enter the home after release from the County Hospital. In this way the residents of Columbia are unlike both the other nursing home residents and the clients of the Project.

Sex distribution was considered as possibly having some bearing on the choice of care, whether it be from an institution or from "community" resources. No significant relationship was found between the Project and McGill Nursing Home, but there was between the Project and Columbia. The two Nursing Homes were also found not to be independent with regard to sex distribution. Whether the significant relationship lies between the Nursing Homes, or between the institutional approach or "community" approach to care and service needs further investigation. 
TABLE IIa

A COMPARISON OF SEX DISTRIBUTION AMONG THE PROJECT

CLIENTS AND INSTITUTIONALIZED PERSONS

\begin{tabular}{lcc}
\hline & Male & Female \\
$\begin{array}{l}\text { Institutionalized } \\
\text { persons (McGill) }\end{array}$ & 11 & 37 \\
Project clients & 379 & 1025 \\
Yule's $Q=0.11, X^{2}=0.432$ (not significant), p<0.05 & Female \\
& $\underline{\text { Male }}$ \\
$\begin{array}{l}\text { Institutionalized } \\
\text { persons (Columbia) }\end{array}$ & 72 & 1025 \\
Project clients & 379 & \\
Yule's $Q=0.73, X^{2}=83.816$ (significant),$p<0.05$ & \\
\hline
\end{tabular}

TABLE IIb

A COMPARISON OF SEX DISTRIBUTION BETWEEN

TWO NURSING HOME GROUPS

\begin{tabular}{lcc}
\hline & $\frac{\text { Male }}{11}$ & $\frac{\text { Female }}{3}$ \\
McGill Residents & 72 & 30 \\
Columbia Residents & & \\
Yule's $Q=0.709, X^{2}=31.80$ (significant), $p<0.05$ & \\
\hline
\end{tabular}

\section{Marital Status}

The marital status data are consistent with the age and sex distributions. The fact that the population receiving services through the Community Project is old and has a high concentration of females suggests that the majority of clients are not currently married. Of the 1,404 
individuals reached by the Project, $30 \%$ were married. However, the elderly clients of the Project were more likely to be married than the residents of the two nursing homes. Looking at the marital status data for the nursing home populations, it was found that at McGill, 23\% were married, and at Columbia, only $9 \%$. The most common marital status for the Project clients was widowhood. Fifty-four percent of this population were widowed. In the two nursing homes, the proportions widowed were $67 \%$ at McGill and $48 \%$ at Columbia. Combining the divorced, separated, and never married statistics, a further comparison can be made. While $14 \%$ of the Project and $10 \%$ of McGill are quite similar, Columbia has a distinctly high $41 \%$ in this category. This could be explained by the high proportion of male transients.

Marital status was examined more closely to see if any significant difference could be accounted for in this area. The first marital status to be considered was the currently married state.

\section{TABLE IIIa}

A COMPARISON OF CURRENT MARRIED STATUS AMONG INSTITUTIONALIZED PERSONS AND THE PROJECT CLIENTS

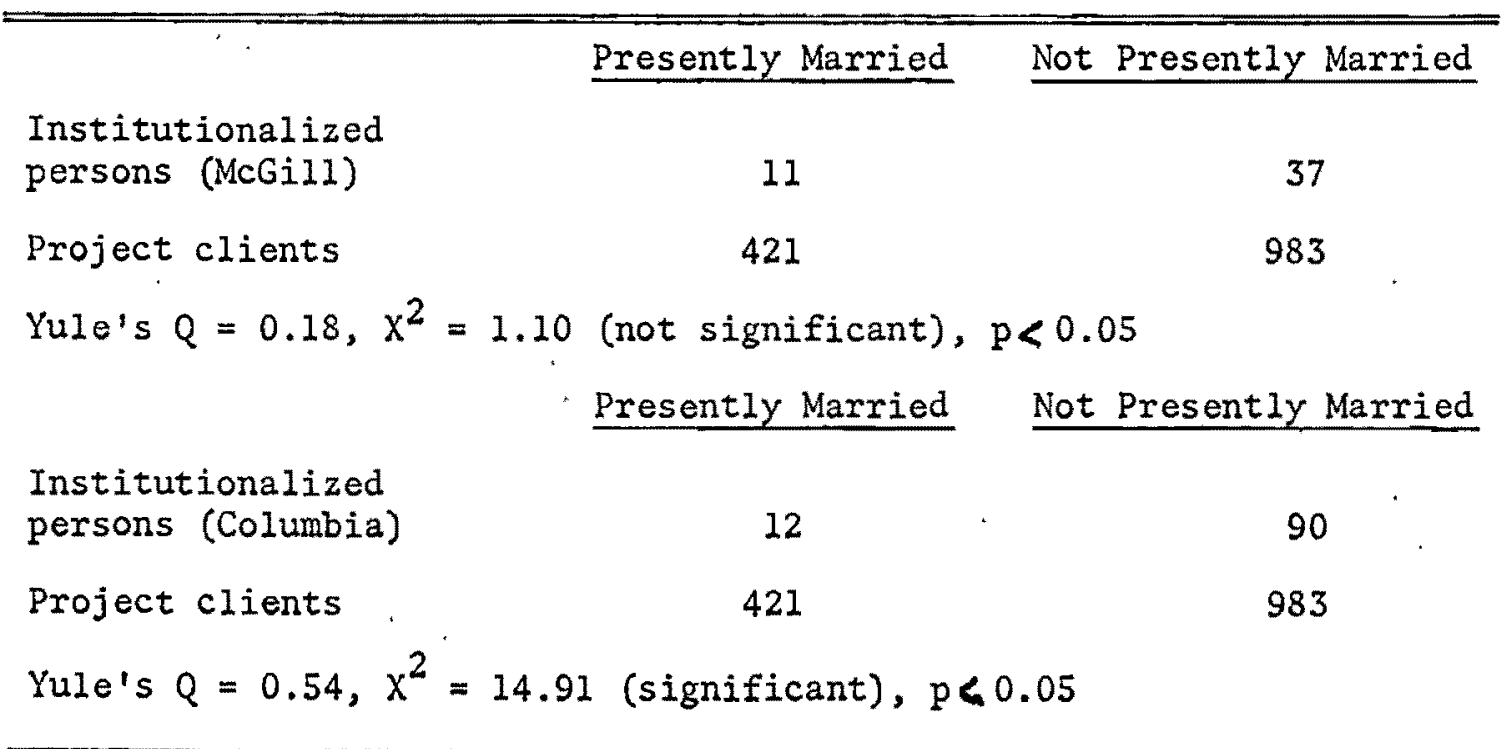


Being currently married appeared as a significant factor between Columbia Nursing Home and the Project clients. However, this was not the case with the McGill patients. There was also no relationship that was significant between the two Nursing Home groups. Further research is needed before a final conclusion could be reached between married status and the type of health system.

TABLE IIIb

\section{A COMPARISON OF CURRENT MARRIED STATUS BETWEEN RESIDENTS OF TWO NURSING HOMES}

\section{Presently Married Not Presently Married}

\section{McGill Residents}

Columbia Residents
11

12
37

90

Yule's $Q=0.38, x^{2}=3.81$ (not significant), $p<0.05$

The groups were also tested for a possible relationship between the widow or widower status and the institutional or non-institutional approach to delivery of needed services. As the following tables show, there is no significant relationship between either of the Nursing Homes with the Community Project system. However, the status of being a widow or widower is not an independent relationship when the two Nursing Homes are compared. 
TABLE IVa

A COMPARISON OF WIDOWED STATUS AMONG INSTITUTIONALIZED

PERSONS AND THE COMMUNITY PROJECT CLIENTS

\begin{tabular}{|c|c|c|}
\hline . & Widowed & Not Widowed \\
\hline $\begin{array}{l}\text { Institutionalized } \\
\text { persons (McGill) }\end{array}$ & 32 & 16 \\
\hline \multirow[t]{2}{*}{ Project clients } & 758 & 646 \\
\hline & $\begin{array}{l}\text { ficant), } \\
\text { Widowed }\end{array}$ & Not Widowed \\
\hline $\begin{array}{l}\text { Institutionalized } \\
\text { persons (Columbia) }\end{array}$ & 39 & 63 \\
\hline Project clients & 758 & 646 \\
\hline Yule's $Q=0.308$ & ficant & \\
\hline
\end{tabular}

TABLE IVb

A COMPARISON OF WIDOWED STATUS BETWEEN RESIDENTS OF TWO NURSING HOMES

\begin{tabular}{lcc}
\hline & $\frac{\text { Widowed }}{1}$ & $\frac{\text { Not Widowed }}{16}$ \\
McGill Residents & 32 & 63 \\
Columbia Residents & 39 & \\
Yule's $Q=0.52, x^{2}=6.01$ (significant), $p<0.05$
\end{tabular}

A final comparison was made in regard to marital status. A relationship between the single, separated, or divorced aged person on the one hand, and the institutionalized and non-institutionalized approach to the delivery of supportive services on the other hand, was sought. No dependent relationship was found with McGill Nursing Home, but a significant relationship was noted between Columbia Home residents and 
the clients of the Project. When both Nursing Homes were compared, they too were found not to be independent with regard to the status of being single, separated or divorced. Here it would seem that the relationship between the Nursing Homes and this facet of marital status is more significant than between the institutional and non-institutional delivery system. However, more research is needed before a definitive conclusion could be made. The results are listed in the following tables.

\section{TABLE Va}

A COMPARISON OF SINGLE, SEPARATED OR DIVORCED MARITAL STATUS AMONG INSTITUTIONALIZED PERSONS AND THE COMMUNITY PROJECT CLIENTS

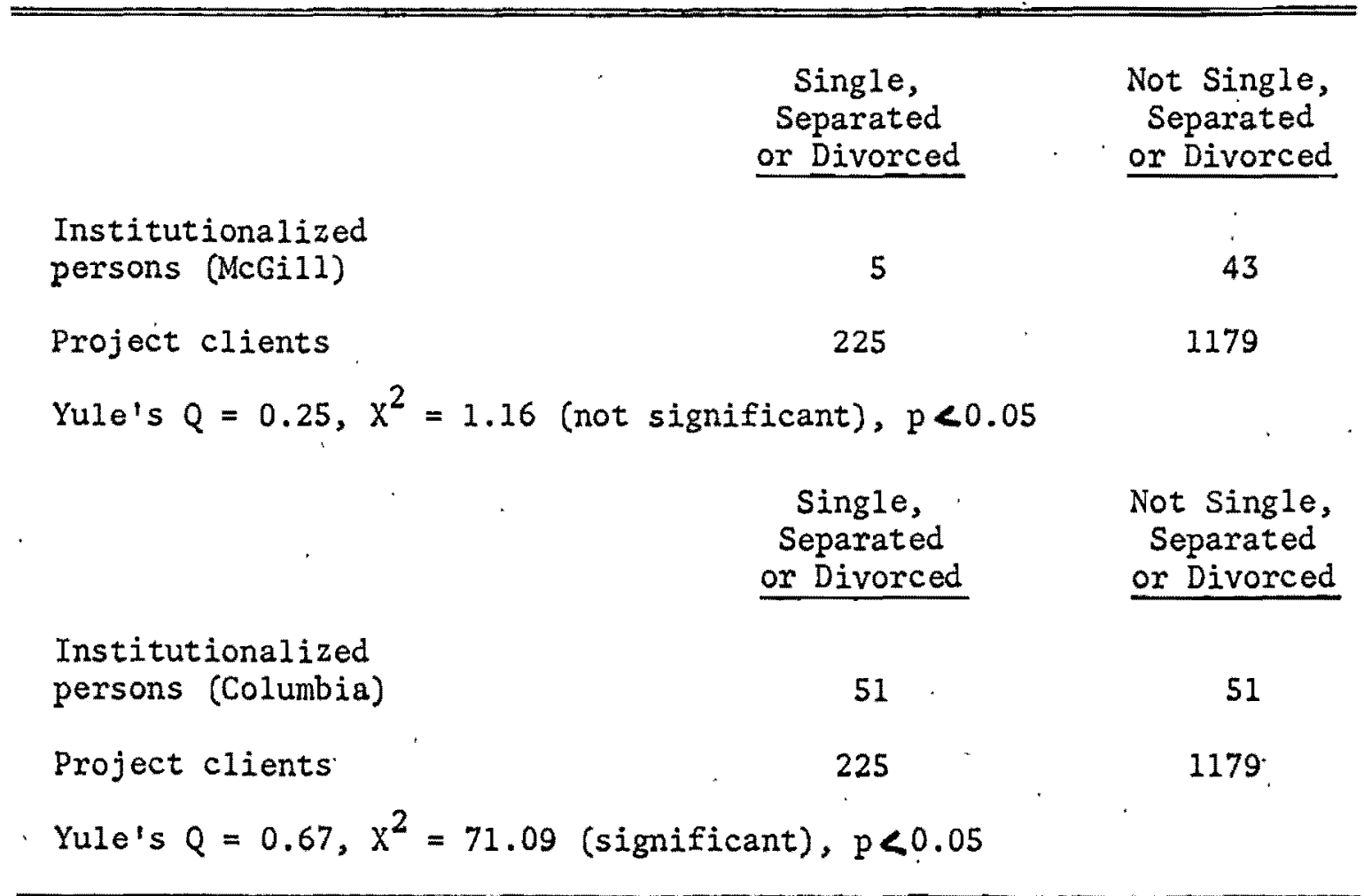


TABLE Vb

A COMPARISON OF SINGLE, SEPARATED OR DIVORCED MARITAL STATUS BETWEEN TWO NURSING HOME GROUPS

\begin{tabular}{lcc}
\hline & $\begin{array}{c}\text { Single, } \\
\text { Separated } \\
\text { or Divorced }\end{array}$ & $\begin{array}{c}\text { Not Single, } \\
\text { Separated } \\
\text { or Divorced }\end{array}$ \\
McGill Residents & 5 & 43 \\
Columbia Residents & 51 & 51 \\
Yule's $Q=0.79, \mathrm{X}^{2}=22.10$ (significant), $\mathrm{p}<0.05$ & \\
\hline
\end{tabular}

TABLE VI

PERCENTAGE DISTRIBUTIONS OF THE THREE POPULATIONS BY AGE GROUPS, BY SEX, BY MARITAL STATUS, AND BY NATIVITY

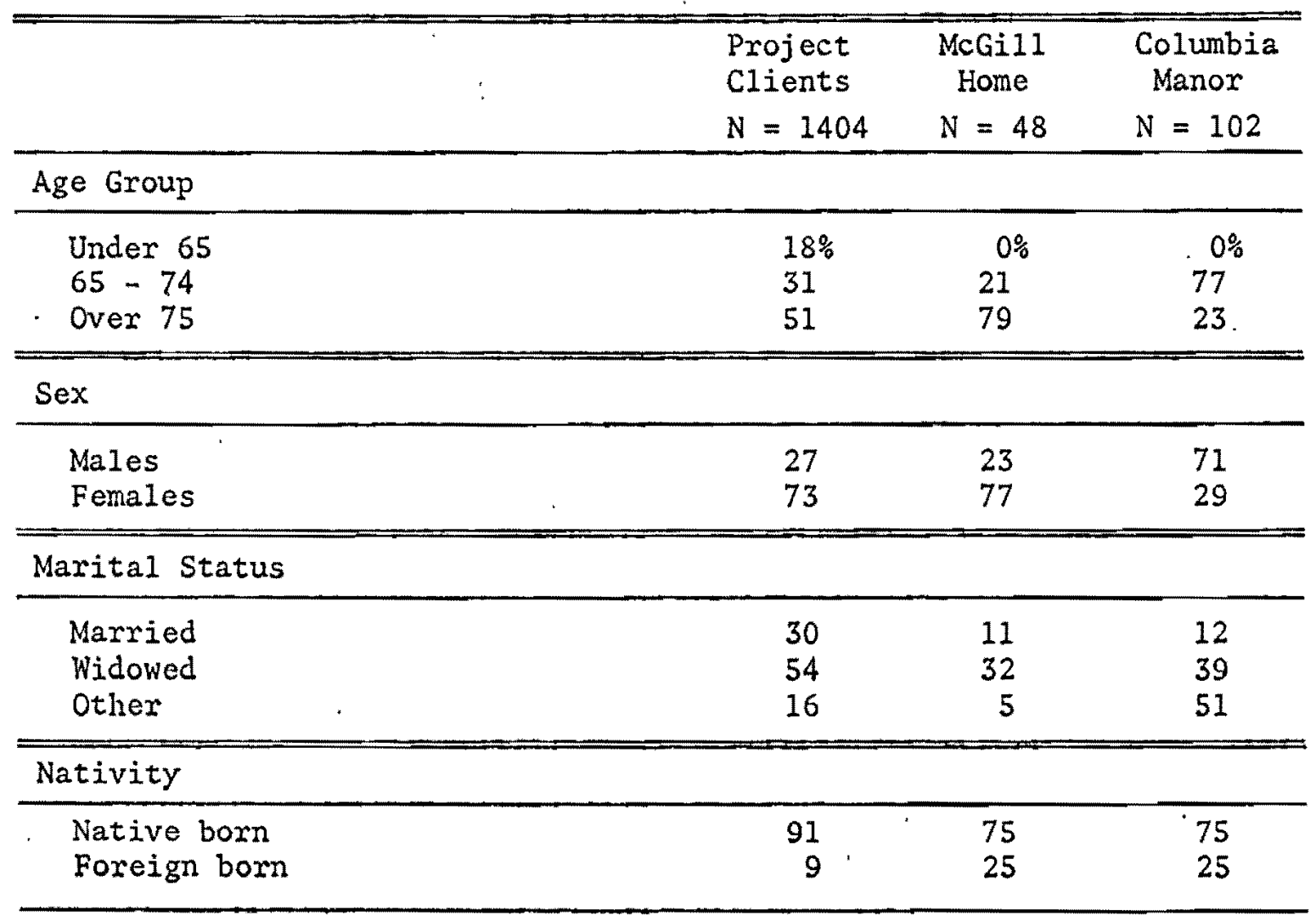




\section{Education}

Education data were available from only one of the nursing homes, McGill, and from the Project clients. Similar educational patterns were noted in both groups. The years of formal schooling are low among older persons. National census reports claim that among persons aged 65 and over, close to half have less than an eighth grade education, and at the opposite extreme, only 4\% graduated from college. In both the institutional and non-institutional populations, the median level of education fell near the completion of high school, which is somewhat higher than could be expected according to the historical circumstances and practices surrounding the older age cohorts. Since it was assumed that the socio-economic status of the Nursing Home group was higher, it was expected that their residents might have a higher level of education. This was not confirmed in the data.

TABLE VII

PERCENTAGE DISTRIBUTION OF TWO GROUPS BY EDUCATION

\begin{tabular}{lcc}
\hline & $\begin{array}{c}\text { Community } \\
\text { Project } \\
\mathrm{N}=1404\end{array}$ & $\begin{array}{c}\text { McGill } \\
\text { Home }\end{array}$ \\
\hline $\begin{array}{l}\mathrm{N}=48 \\
\text { Formal Education }\end{array}$ & $13 \%$ & $13 \%$ \\
Less than 8 years & 32 & 29 \\
Finished Grade Schoo1 & 12 & 8 \\
Some High School & 24 & 25 \\
Finished High School & 8 & 5 \\
Technical Training & 11 & 20 \\
College Work & & 5 \\
\hline
\end{tabular}


Income

A crucial factor influencing the quality of housing and health care is adequate income. Income data were available on four-fifths of the older adults reached by the Project. The data revealed that the median income of the Project clients was $\$ 150.00$ per month. Fourteen percent of these individuals lived in households with an income below $\$ 100.00$ and $16 \%$ were in homes with an income above $\$ 250.00$ monthly. Applying. the poverty indicator to Project clients reveals that half of all of the older adults reached by the Project were living in households with incomes below poverty level. The poverty cutoff amount is approximately $\$ 150.00$ per month. Data on monthly income were not available for the residents of the two homes. However, considering McGill's high rates and low proportion of public assistance recipients, it can be assumed that the income of the majority of patients was not below the poverty level. In Columbia, on the other hand, the majority of residents are financially supported by public assistance payments and hence it is expected that their incomes would closely approximate the financial status of Project ABLE's clients.

\section{B. LIVING ARRANGEMENTS AND HOUSING}

Living arrangements were consistent with the marital status data of all three populations. Since the majority of individuals in the three groups were widowed, divorced or never married, it was expected that most would live alone. This expectation proved true in two groups--the Project ABLE clients and the residents of Columbia Manor.

Sixty-three percent of the Project clients lived alone, 26\% lived with a spouse, 3\% with their children (and no spouse present), and $7 \%$ 
lived with others. Data from Columbia showed that $75 \%$ of the patients reported living alone before their admittance to this institution. Seven percent lived with a spouse, $14 \%$ with children and $4 \%$ with others. However, records from McGill showed that prior to entering the institution, $42 \%$ lived alone, $21 \%$ with a spouse, $13 \%$ lived with children, and $24 \%$ with others.

Hence the data on living arrangements reveal that wide variations exist between the two nursing home groups as well as between the home residents and the Project clients. Generally it is assumed that living alone poses the most serious threat to community-based living, but the fact that less than half of the residents in McGill were living alone casts doubt on this assumption. It may also be the case that living with children or others who are not able or willing to care for the elderly individual is likely to result in institutionalization. Other possible reasons for this higher percentage living with others at McGill may be due to dependency needs contingent on health reasons, or the ability to pay for live-in homemakers, due to a higher income level, or perhaps even a difference in close family interaction. Some of these possible reasons will be investigated to see if there is any statistical significance.

Census data from Multnomah County reveal that only $33 \%$ of the residents over 65 are living alone. Here all three of these populations are not consistent with those national statistics, and especially it can be noted that the Project has reached twice as many elderly living alone as would have been found in a random selection of clients from within the County or the country. 
Of the Project clients, $49 \%$ lived in a house and $41 \%$ of these homes were client owned. Another $42 \%$ lived in an apartment, and almost half of these were rented from public housing. Seven percent of this population lived in a rooming house. The residents of McGill were questioned about their last residence before admittance to this health care facility. A much higher proportion, $80 \%$, lived in a house, and this was client owned by $67 \%$. Seventeen percent lived in an apartment, and only $2 \%$ lived in a rooming situation. However, in this nursing home group, a minority rented a home. Perhaps this fact could give credence. to the belief that this group is of higher economic status than the clients of the Community Project.

In regard to the household facilities of a stove, refrigerator, plumbing and telephone, while the McGill residents reported ownership of all these items, the Project clients did not. Ninety-six percent of the Community clients reported having a stove, $95 \%$ a refrigerator, $96 \%$ plumbing, and 91\% a telephone. Housing information was not available from the residents of Columbia Manor. 


\section{TABLE VIII}

PERCENTAGE DISTRIBUTIONS OF. THREE POPULATIONS BY MARITAL STATUS, LIVING ARRANGEMENTS AND HOUSING SITUATION

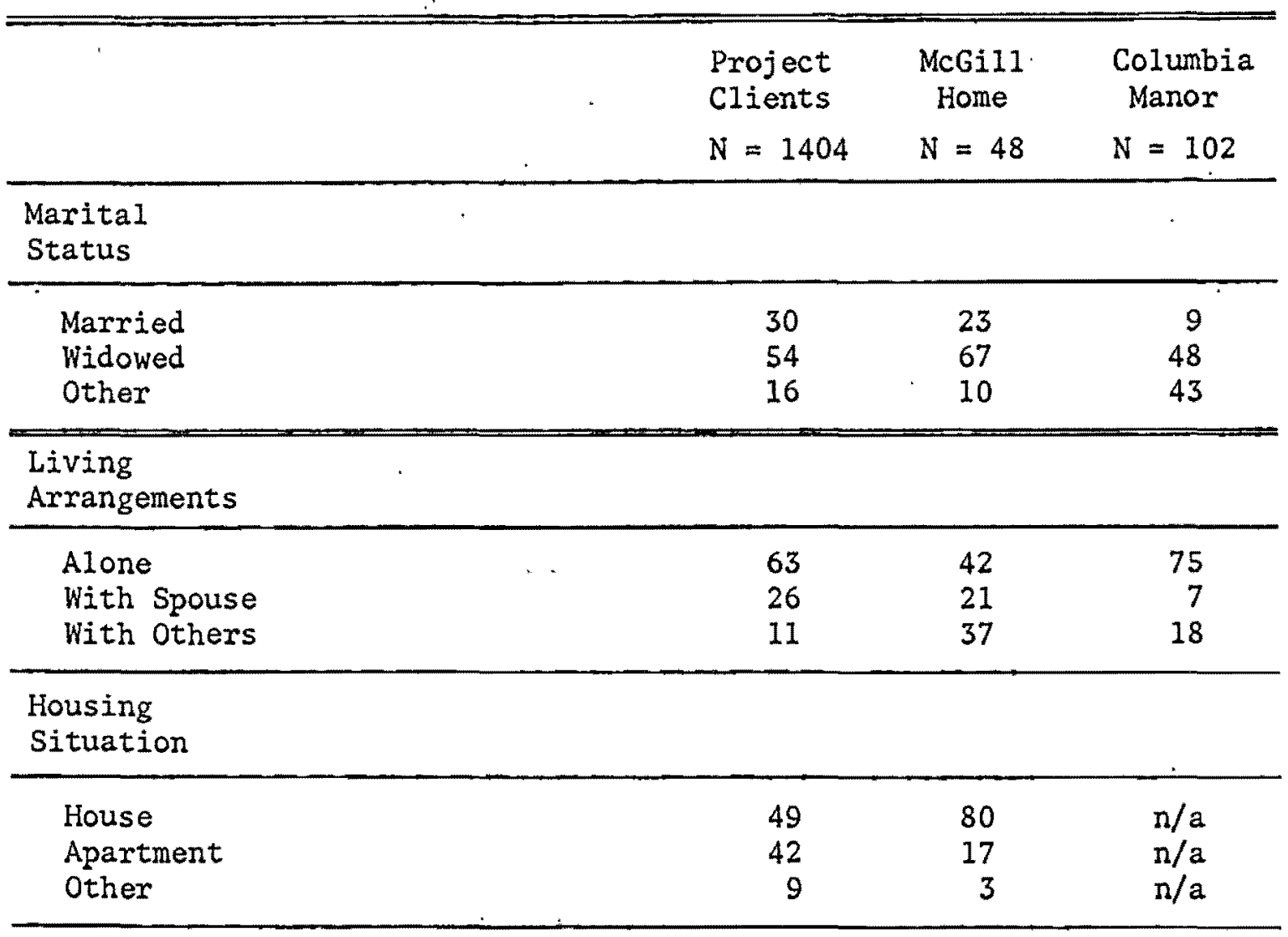

Living arrangements was another variable that was submitted to a test of significance. Three aspects of living arrangements were examined: living alone, living with a spouse and living with others.

Living alone appeared to be a significant difference when comparing the institutionalized groups and the Project clients. However, when the two nursing home groups were compared, it also appeared to be a significant variable, with even a stronger relationship as noted by the Yule's $Q$ measure. Further research is needed to ascertain its definitive role in comparing the two health delivery systems under study. 
TABLE IXa

A COMPARISON OF LIVING ALONE AMONG INSTITUTIONALIZED

AND NON-INSTITUTIONALIZED PERSONS

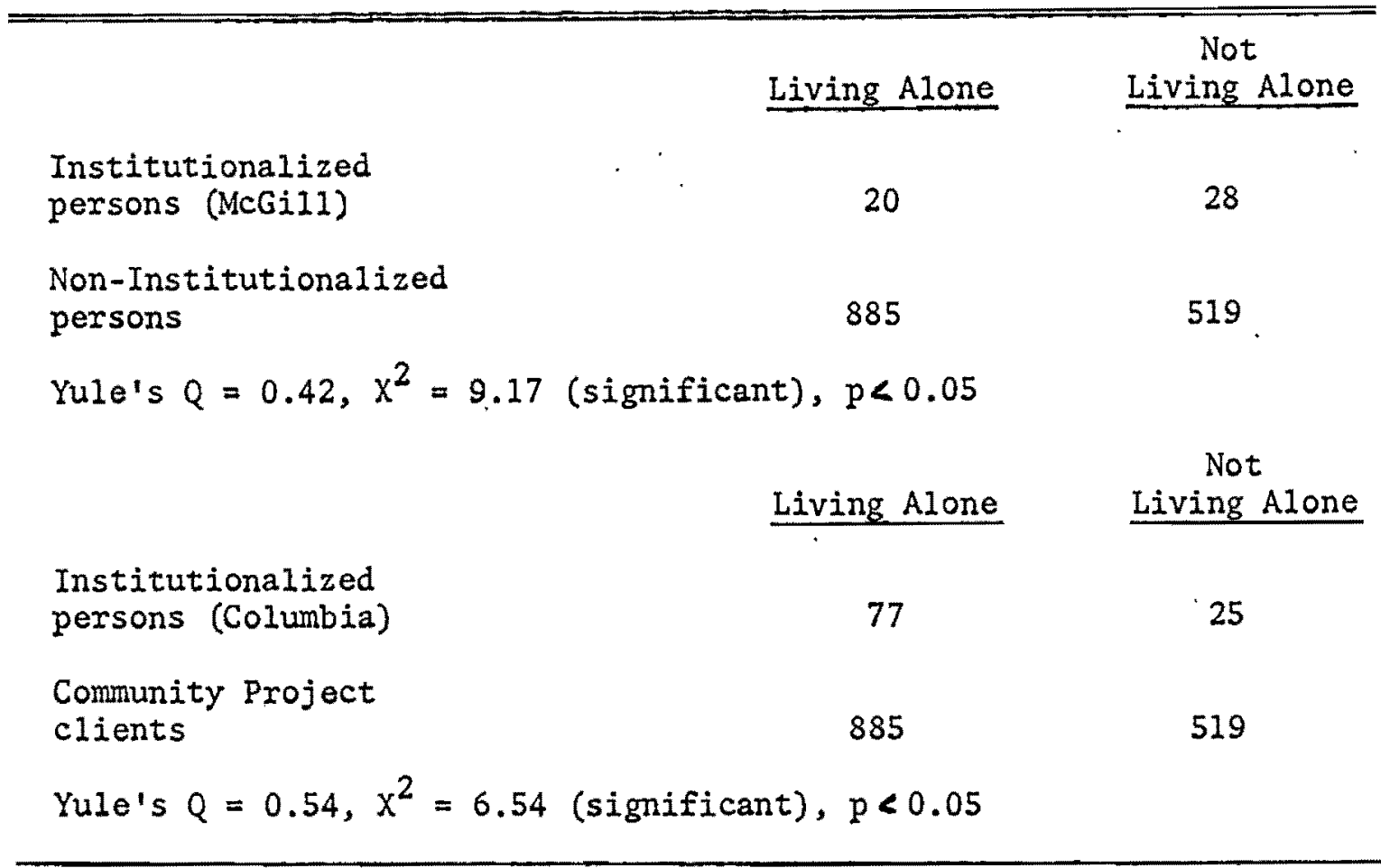

TABLE IXb

A COMPARISON OF LIVING ALONE BETWEEN RESIDENTS

OF TWO NURSING HOMES

\begin{tabular}{lcc}
\hline & Living Alone \\
McGill Residents & 20 & $\begin{array}{c}\text { Not } \\
\text { Living Alone }\end{array}$ \\
Columbia Residents & 77 & 28 \\
Yule's $Q=0.62, X^{2}=16.17$ (significant), $p<0.05$
\end{tabular}

Living with a spouse appeared to be significant in Columbia Nursing Home, but not with McGill Nursing Home, when both were compared to the clients of the Project. Both Nursing Homes were compared and living with 
a spouse appeared to be a significant factor which differentiated both populations. In order to ascertain if a relationship does exist between living with a spouse and the health delivery system, whether it be an institutional approach or a "community" approach, would need additional research and study.

TABLE Xa

A COMPARISON OF LIVING WITH A SPOUSE AMONG INSTITUTIONALIZED PERSONS AND THE PROJECT CLIENTS.

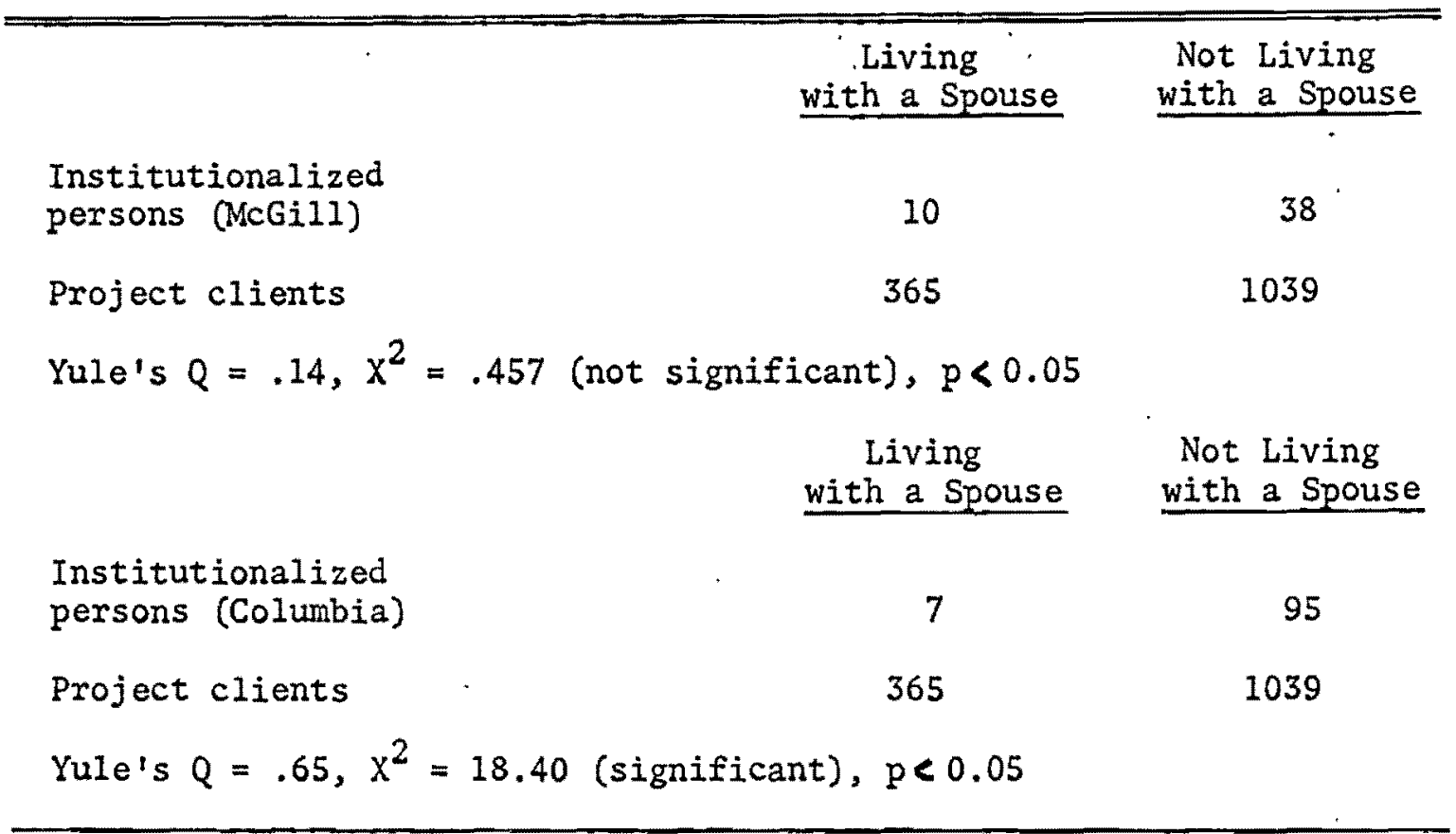

TABLE $\mathrm{Xb}$

A COMPARISON OF LIVING WITH A SPOUSE BETWEEN THE RESIDENTS OF TWO NURSING HOMES

\begin{tabular}{lcc}
\hline & $\begin{array}{c}\text { Living } \\
\text { with a Spouse }\end{array}$ & $\begin{array}{c}\text { Not Living } \\
\text { with a Spouse }\end{array}$ \\
\cline { 2 - 3 } & 10 & 38 \\
Columbia Residents & 7 & 95 \\
Yule's $Q=.56, x^{2}=7.93$ (significant), $p<0.05$ \\
\hline
\end{tabular}


Living with others (not a spouse) was noted as significant with one Nursing Home group when compared to the Project clients. However, it was not significant with Columbia Nursing Home residents. When both nursing homes were compared to see if living with others was significant, the finding was positive. No definite conclusions can thus be formed. Further research is needed to uncover if living with others is related to the type of health delivery system one calls upon, whether it be an institutional approach or a "community" approach.

TABLE XIa

A COMPARISON OF LIVING WITH OTHERS AMONG THE COMMUNITY PROJECT CLIENTS AND INSTITUTIONALIZED PERSONS

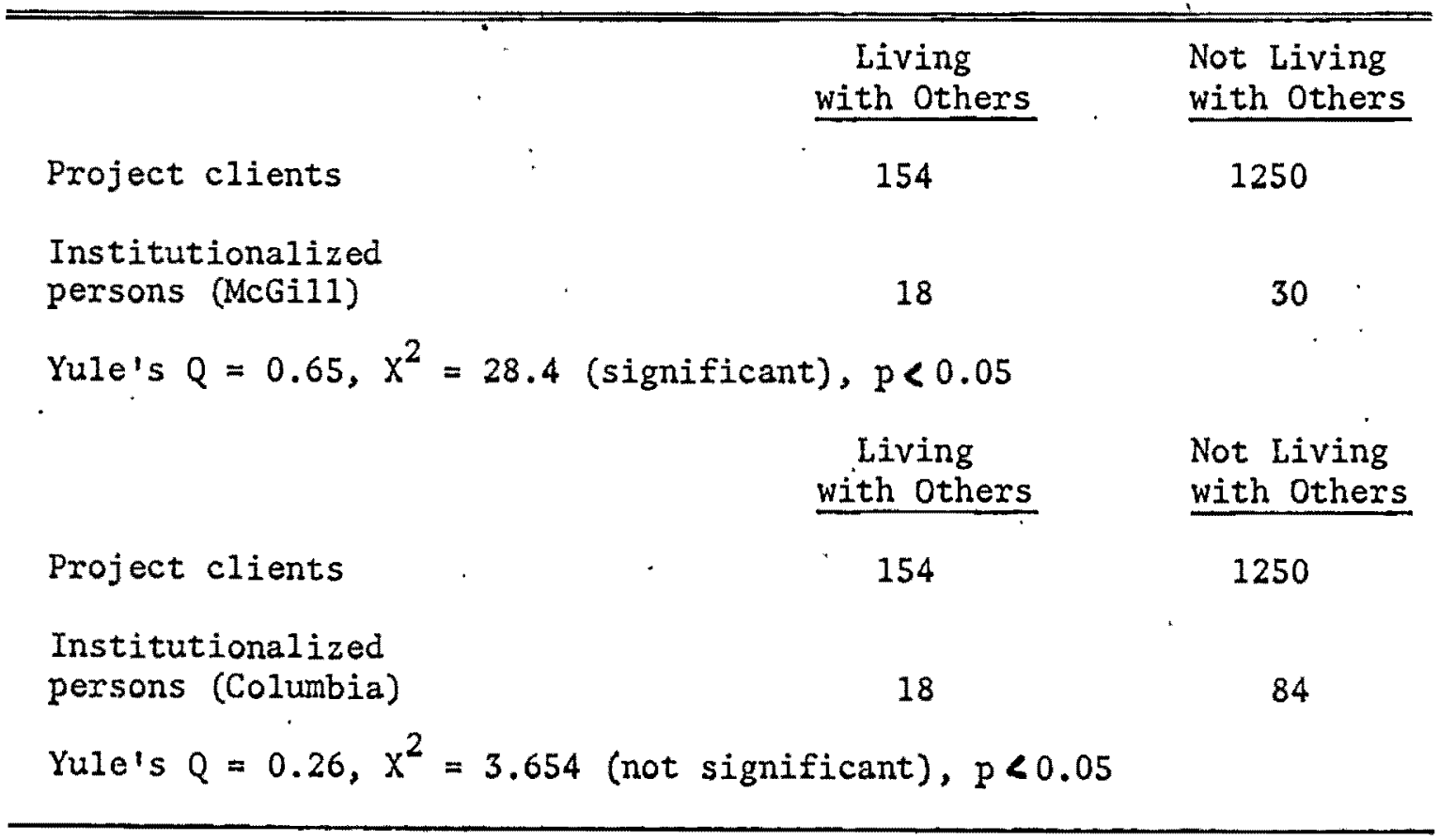


TABLE XIb

A COMPARISON OF LIVING WITH OTHERS BETWEEN THE RESIDENTS OF TWO NURSING HOMES

\begin{tabular}{lcc}
\hline & $\begin{array}{c}\text { Living } \\
\text { with Others }\end{array}$ & $\begin{array}{c}\text { Not Living } \\
\text { with Others }\end{array}$ \\
McGill Residents & 18 & 30 \\
Columbia Residents & 18 & 84 \\
Yule's $Q=.47, \mathrm{X}^{2}=4.03$ (significant), $p<0.05$
\end{tabular}

\section{SOCIAL CONTACTS}

The older adults in both the institutionalized and client groups reported a lack of contact with children. The residents of McGill Nursing Home and the clients of the Project were asked directly how often they saw their children, relatives and friends. By using the recorded listing of children, relatives and friends, which is filled out on admittance to Columbia Manor, it was possible to estimate very roughly the number of close contacts the patients had.

Forty-four percent of the residents of McGill and $51 \%$ of those in Columbia reported no contact with children when they were residing in the community. These figures include the elderly clients and residents who reported having no living children. Data on the amount of interaction with other persons revealed that the Project clients were less likely to be isolated from relatives and friends than the institutionalized group had been prior to admission. Forty-nine percent of the residents in McGill and $63 \%$ of those in Columbia reported no social contacts with relatives. In comparison, $30 \%$ of the Project clients reported no interaction with relatives. Only $11 \%$ of the clients had no contact with 
friends, whereas $28 \%$ of McGill residents and $72 \%$ of Columbia residents reported no interaction with friends.

McGi11 Nursing Home residents and the Project clients were questioned on their feelings about the need for more contacts and about their personal feelings concerning loneliness. Only $8 \%$ of the Nursing Home population felt they had experienced loneliness either occasionally or most of the time. Eight percent of this same group had recently had the experience of losing someone close to them in death. Thirty-four percent of the Project population admitted feeling isolated and in need of more social interaction. Six percent had recently suffered the loss of a relative or close friend in death.

These statistics about the apparent lack of intense social interaction of the clients of the community population are not too surprising, since the focus of the project is to reach older adults living alone. Since the population reached also contains half living with incomes below the poverty level, it could be assumed expenses used for traveling and communication would be at a minimum. Also considering the demographic data, it was found only $22 \%$ were born in the Northwest, while the largest percentage, $37 \%$, originated in the Midwest. This fact too may have consequences for fewer close relatives. A look at the health status of the population may give further insights into the low rate of close social interaction.

The mode of transportation is also determined by the income level and can affect social interaction. Since it has been noted that half of the older adults reached by the Project were living in households with incomes below the poverty level, it was expected that data would reveal that the kind and use of transportation would be an area of need. A lack 
of transportation can limit a person's environment. Available services may become unobtainable for the individual who has no transportation. The usage of public medical facilities, the opportunity for comparative shopping and perhaps the ability to obtain abundant foods may all become problematic areas.

Transportation data on 1,404 persons contacting the Project showed that $45 \%$ of this population presented transportation as a problematic area, and $47 \%$ of this group were referred for Transportation services. Eighteen percent needed transportation to visit friends or relatives, $12 \%$ to attend church, $39 \%$ to go to a store and $70 \%$ to reach medical facilities. Data on the types of transportation now being used report that $9 \%$ own their own automobile, $43 \%$ use another automobile, $11 \%$ rely on a taxi service, $8 \%$ depend on a transportation program and $30 \%$ use public transportation. For $19 \%$ walking is the only means of transportation. Thus it can be seen only a small minority, $9 \%$, are self-sufficient in their use of transportation. Another $4 \%$ responded they use no transportation as they never go out.

When questioned on transportation assistance now available, 4\% cited a spouse, $14 \%$ a relative, $15 \%$ a friend or neighbor, and $44 \%$ professional assistance. Sixty-nine percent of the respondents requested a want for transportation assistance.

A limited amount of data dealing with transportation was available from the McGill Nursing Home group. Before their admittance, $52 \%$ reported they were able to use public transportation alone, $23 \%$ with help, and $10 \%$ not at all. Since their admittance, $2 \%$ of these same respondents noted a positive change in their ability to use public transportation, $27 \%$ felt no change, while $42 \%$ commented on a negative change. 
From these limited statistics, it can be seen that transportation is a problematic area. The institutionalized group, however, viewed transportation as more of a physical problem rather than as a social or financial problem.

\section{TABLE XII}

PERCENTAGE DISTRIBUTION OF THREE POPULATIONS IN REGARD TO SOCIAL CONTACTS WITH CHILDREN, RELATIVES, AND FRIENDS

\begin{tabular}{lccc}
\hline & $\begin{array}{l}\text { Project } \\
\text { Client } \\
\mathrm{N}=787\end{array}$ & $\begin{array}{c}\text { McGil1 } \\
\text { Home } \\
\mathrm{N}=48\end{array}$ & $\begin{array}{c}\text { Columbia } \\
\text { Manor }\end{array}$ \\
\hline SOCIAL CONTACT & & & $\mathrm{N}=102$ \\
\hline $\begin{array}{l}\text { No Contacts } \\
\text { wi.th Children }\end{array}$ & $44 \%$ & $26 \%$ & $51 \%$ \\
$\begin{array}{l}\text { No Contacts } \\
\text { with Relatives }\end{array}$ & $30 \%$ & $49 \%$ & $63 \%$ \\
$\begin{array}{l}\text { No Contacts } \\
\text { with Friends }\end{array}$ & $11 \%$ & $28 \%$ & $72 \%$ \\
\hline
\end{tabular}

Social relationships were seen to be important and worth looking at more closely. Social relationships with children, relatives and friends were examined in turn, comparing the Community Project clients with each of the Nursing Homes. The two Homes were compared with each other in this area lest a significant difference was a consequence of one of the Nursing Homes rather than a possible measure of difference between an institutional group and a "community group."

Social relationships with children, relatives and friends were defined operationally as having contact with, and a lack of social rela- 
tionship was defined as having no contact with children, relatives, or friends.

The first area looked at was social contact with children. The following tables note the significance or lack of significance of a possible relationship, and Yule's $Q$ notes the specific strength of relationship.

TABLE XIIIa

A COMPARISON OF SOCIAL CONTACT WITH CHILDREN AMONG

INSTITUTIONALIZED PERSONS AND THE

PROJECT CLIENTS

\begin{tabular}{|c|c|c|}
\hline & $\begin{array}{c}\text { Social } \\
\text { Contact } \\
\text { with Children } \\
\end{array}$ & $\begin{array}{c}\text { No Social } \\
\text { Contact } \\
\text { with Children } \\
\end{array}$ \\
\hline $\begin{array}{l}\text { Institutionalized } \\
\text { perșons (McGil1) }\end{array}$ & 36 & 12 \\
\hline Project clients & 441 & 346 \\
\hline \multicolumn{3}{|c|}{ Yule's $Q=.403, x^{2}=6.41$ (significant), $p<0.05$} \\
\hline . & $\begin{array}{r}\text { Social } \\
\text { Contact } \\
\text { with Children } \\
\end{array}$ & $\begin{array}{c}\text { No Social } \\
\text { Contact } \\
\text { with Children } \\
\end{array}$ \\
\hline $\begin{array}{l}\text { Institutionalized } \\
\text { persons (Columbia) }\end{array}$ & 49 & 53 \\
\hline Project clients & 441 & . 346 \\
\hline
\end{tabular}


TABLE XIIIb

A COMPARISON OF SOCIAL CONTACT WITH CHILDREN

BETWEEN TWO NURSING HOME GROUPS

\begin{tabular}{lcc}
\hline McGill Residents & $\begin{array}{c}\text { Social } \\
\text { Contact } \\
\text { with Children }\end{array}$ & $\begin{array}{c}\text { No Social } \\
\text { Contact } \\
\text { with Children }\end{array}$ \\
Columbia Residents & 35 & 12 \\
Yule's $Q=.49, X^{2}=11.1$ (significant), $p<0.05$ & 53 \\
\hline
\end{tabular}

From the tables, it can be seen that a significant relationship does exist between McGill Nursing Home and the Project clients, but not with Columbia residents. Since both nursing homes are also significantly different in relation to social contacts with children, once again no definitive statement can be made concerning the relation of social contacts with children and the two different approaches to health services. From the results the differences between the two Home groups might explain the variance, and not the institutional or non-institutional approach to care and services.

Social contacts, with relatives and health care delivery systems cannot be viewed as independent factors, with regard to these three groups. A significant relationship was noted between the community delivery system, and with each of the nursing home groups, as can be seen from the following tables. 
TABLE XIVa

A COMPARISON OF SOCIAL CONTACTS WITH RELATIVES AMONG INSTITUTIONALIZED PERSONS AND PROJECT CLIENTS

\begin{tabular}{|c|c|c|}
\hline . & $\begin{array}{c}\text { Social } \\
\text { Contact } \\
\text { with Relatives } \\
\end{array}$ & $\begin{array}{c}\text { No Social } \\
\text { Contact } \\
\text { with Relatives } \\
\end{array}$ \\
\hline $\begin{array}{l}\text { Institutionalized } \\
\text { persons (McGill) }\end{array}$ & 25 & 23 \\
\hline Project clients & 551 & 236 \\
\hline & $\begin{array}{c}\text { Social } \\
\text { Contact } \\
\text { with Relatives } \\
\end{array}$ & $\begin{array}{c}\text { No Social } \\
\text { Contact } \\
\text { with Relatives } \\
\end{array}$ \\
\hline $\begin{array}{l}\text { Institutionalized } \\
\text { persons (Columbia) }\end{array}$ & 38 & 64 \\
\hline Project clients & 551 & 236 \\
\hline
\end{tabular}

TABLE XIVb

A COMPARISON OF SOCIAL CONTACTS WITH RELATIVES BETWEEN TWO NURSING HOME GROUPS

\begin{tabular}{lcc}
\hline McGill Residents & $\begin{array}{c}\text { Social } \\
\text { Contact } \\
\text { with Relatives }\end{array}$ & $\begin{array}{c}\text { No Social } \\
\text { Contact } \\
\text { with Relatives }\end{array}$ \\
Columbia Residents & 25 & 23 \\
Yule's $Q=.29, x^{2}=3.20$ (not significant), $p<0.05$ & 64 \\
\hline
\end{tabular}

When both nursing homes were examined for a relationship between social contacts with relatives and a difference of environment, no sig- 
nificant relationship could be found. This strengthened the conclusion that the aged persons served by an institution might differ with regard to social contact with relatives. At least this relationship should be looked at more carefully in further research.

A similar relationship was found to exist in regard to social contact with friends. This factor appeared to be significantly different among the institutionalized groups and the clients of the Project. This difference also is a much stronger measure, as can be noted from the higher values of Yule's $Q$, which are 0.91 and 0.90 , respectively. These results are summarized in the tables below.

TABLE XVa

A COMPARISON OF SOCIAL CONTACTS WITH FRIENDS AMONG INSTITUTIONALIZED PERSONS AND CLIENTS

\begin{tabular}{|c|c|c|}
\hline & $\begin{array}{l}\text { Social } \\
\text { Contacts } \\
\text { with Friends } \\
\end{array}$ & $\begin{array}{r}\text { No Social } \\
\text { Contacts } \\
\text { with Friends } \\
\end{array}$ \\
\hline \multicolumn{3}{|l|}{$\begin{array}{l}\text { Institutionalized } \\
\text { persons (McGill) }\end{array}$} \\
\hline Project clients & 700 & 87 \\
\hline \multicolumn{3}{|c|}{ Yule's $Q=0.91, x^{2}=139.09$ (significant), $p<0.05$} \\
\hline & $\begin{array}{c}\text { Social } \\
\text { Contacts } \\
\text { with Friends } \\
\end{array}$ & $\begin{array}{l}\text { No Social } \\
\text { Contacts } \\
\text { with Friends } \\
\end{array}$ \\
\hline \multicolumn{3}{|l|}{$\begin{array}{l}\text { Institutionalized } \\
\text { persons (Columbia) }\end{array}$} \\
\hline Project clients & 700 & 87 \\
\hline Yule's $Q=0.90, X^{2}$ & ificant), $p<$ & \\
\hline
\end{tabular}


TABLE XVB

A COMPARISON OF SOCIAL CONTACTS WITH FRIENDS

BETWEEN TWO NURSING HOMES

\begin{tabular}{lcc}
\hline McGill Residents & $\begin{array}{c}\text { Social } \\
\text { Contacts } \\
\text { with Friends }\end{array}$ & $\begin{array}{c}\text { No Social } \\
\text { Contacts } \\
\text { with Friends }\end{array}$ \\
Columbia Residents & 13 & 35 \\
Yule's $Q=.033, X^{2}=0$ (not significant), $p<0.05$ & 73 \\
\hline
\end{tabular}

The two nursing home groups were likewise tested but no significant relation was found. This again strengthened the conclusion that social contact with friends is an important variable to consider in distinguishing aged persons receiving services through an institution and those receiving supportive services via a community delivery system. Further research should include this relationship.

\section{HEALTH STATUS}

\section{Physical Health}

In general, both the Project clients and the nursing home residents were plagued with physical health problems. Chronic conditions were reported by $72 \%$ of the Project clients. Eighty percent of the residents of McGill were diagnosed as having a chronic illness at the time of intake. A similar proportion, $77 \%$, of Columbia's residents suffered from chronic illnesses.

The most substantial difference in physical health between the Project population and the Home residents was evidenced in recent hospitali- 
zations. Hospitalization typically occurred in response to an acute health need. Whereas $30 \%$ of the Project clients had been hospitalized during the year prior to intake, records on the nursing home residents revealed that $61 \%$ at MCGill and $77 \%$ at Columbia had been hospitalized prior to admission. These data indicate that the primary healthrelated difference between the Project clients and nursing home residents is not the presence of a chronic health problem but the onset of an acute illness requiring hospitalization.

Physical health problems are also evidenced in mobility limitations. The Project and nursing home populations were classified as ambulatory, semi-ambulatory (needs assistance of wheelchair, walker, another person) and home or bed bound. The three groups showed very little difference in mobility limitations. Sixty-six percent of the Community Project clients were ambulatory, $20 \%$ were semi-ambulatory, and $14 \%$ were confined to home or bed. At McGill, the distribution was $61 \%$ ambulatory, $32 \%$ semi-ambulatory and $7 \%$ confined, and at Columbia the respective distributions were $67 \%, 25 \%$ and $8 \%$.

Another comparative tool which gives some insight into the physical condition of the two groups are the self-maintenance ratings. Complete comparisons can only be made between the Project clients and the residents of McGill Nursing Home. Among the problem areas cited by the Project clients, $42 \%$ felt they needed help shopping, $34 \%$ with 1 ight housekeeping, $32 \%$ with meal preparation, $11 \%$ with personal care and $9 \%$ felt they needed help in taking medications. Looking at the Nursing Home population, $57 \%$ cited help was needed for shopping, $57 \%$ with 1 ight housekeeping, $48 \%$ with meal preparation, $45 \%$ with personal care and $35 \%$ with medications. Thus it can be seen that the "community" population 
was less in need in a11 areas than the institutionalized group. However, it is evident that with both groups, help is needed by many of the elderly in basic service areas such as is focused on by the Community Project.

\section{TABLE XVI}

PERCENTAGE DISTRIBUTIONS OF THREE POPULATIONS WITH REGARD TO PHYSICAL HEALTH, HOSPITALIZATION AND MOBILITY

\begin{tabular}{|c|c|c|c|}
\hline & $\begin{array}{l}\text { Project } \\
\text { Clients }\end{array}$ & $\begin{array}{c}\text { McGill } \\
\text { Home }\end{array}$ & $\begin{array}{l}\text { Colunibia } \\
\text { Manor }\end{array}$ \\
\hline & $N=787$ & $N=48$ & $N=102$ \\
\hline \multicolumn{4}{|l|}{ Physical Health } \\
\hline $\begin{array}{l}\text { Presence of } \\
\text { chronic } \\
\text { condition }\end{array}$ & $73 \%$ & $80 \%$ & $77 \%$ \\
\hline \multicolumn{4}{|l|}{ Hospitalizations } \\
\hline $\begin{array}{l}\text { Admitted in } \\
\text { past year }\end{array}$ & $30 \%$ & $61 \%$ & $77 \%$ \\
\hline \multicolumn{4}{|l|}{ Mobility } \\
\hline $\begin{array}{l}\text { Ambulatory } \\
\text { Semi-ambulatory } \\
\text { Home or bed bound }\end{array}$ & $\begin{array}{l}66 \% \\
20 \\
14\end{array}$ & $\begin{array}{l}61 \% \\
32 \\
7\end{array}$ & $\begin{array}{l}62 \% \\
26 \\
11\end{array}$ \\
\hline
\end{tabular}

Physical health was measured according to chronic illness, mobility and recent hospitalization. Each of these variables in turn was analyzed to see if a relationship existed between that variable and the type of environment chosen for supportive services, whether it be an institution or a "community" system. From the following tables, it is evident no. relationship was found to exist when the two institutional groups were each compared to the "community" group in regard to chronic illness and 
mobility. Both Nursing Homes too were tested for a relationship between themselves and chronic illness and mobility. No significant relationship was found, as can be seen from the following tables.

TABLE XVIIa

A COMPARISON OF THE RELATIONSHIP OF CHRONIC ILLNESS AMONG THE PROJECT CLIENTS AND INSTITUTIONALIZED PERSONS

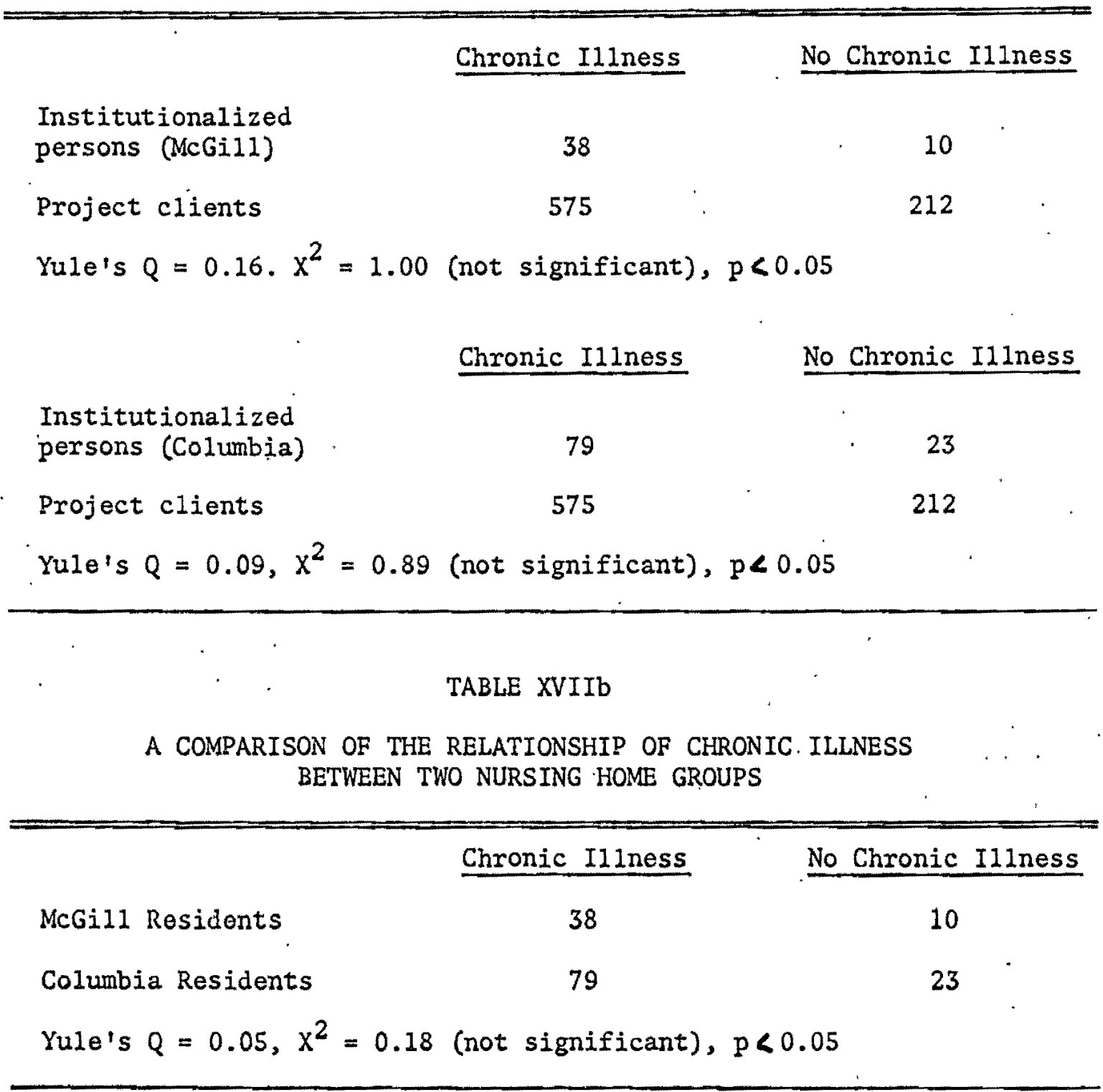


TABLE XVIIIa

A COMPARISON OF THE RELATIONSHIP OF MOBILITY AMONG

INSTITUTIONALIZED PERSONS AND THE

COMMUNITY PROJECT CLIENTS

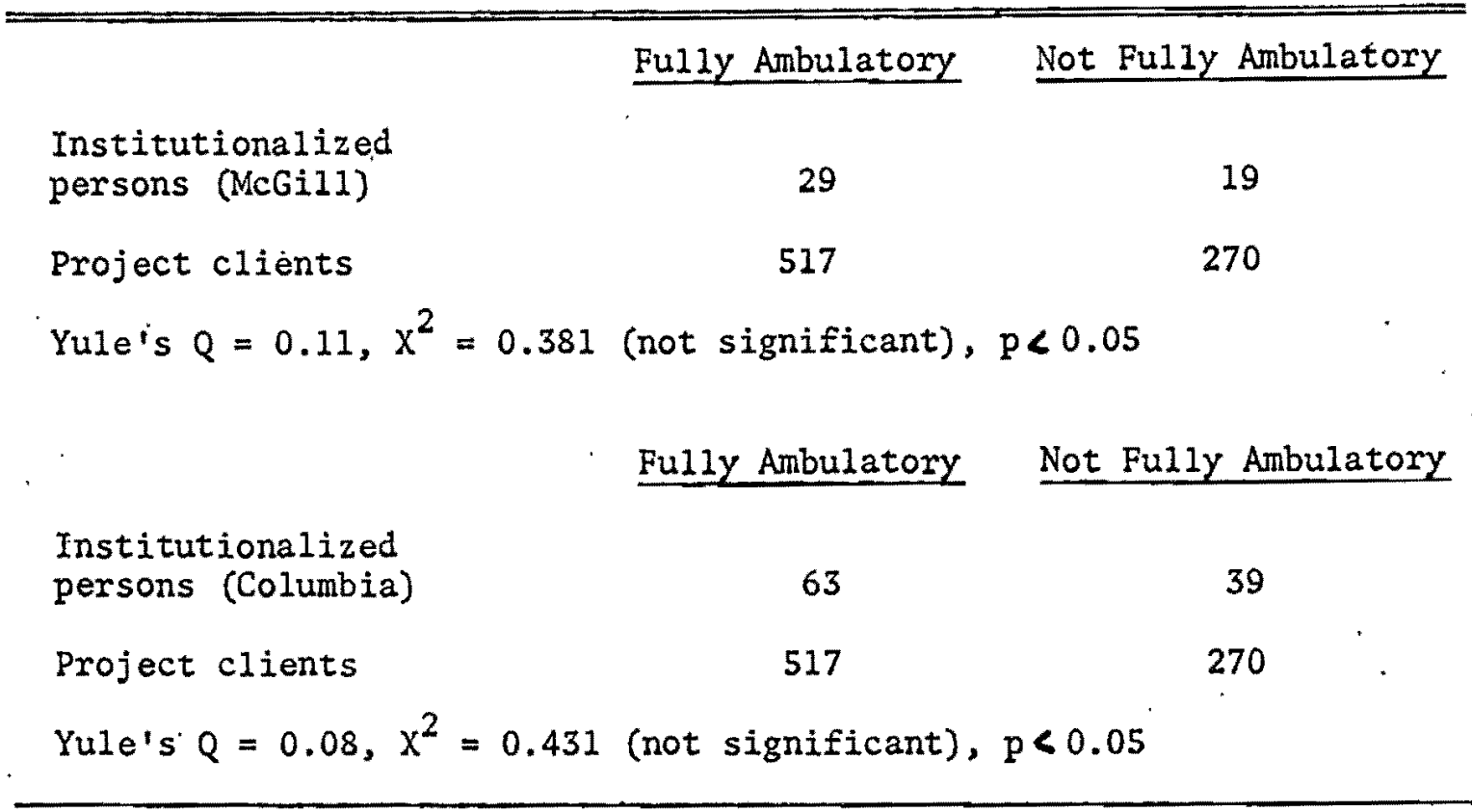

TABLE XVIIIb

A COMPARISON OF THE RELATIONSHIP OF MOBILITY BETWEEN TWO NURSING HOME GROUPS

\begin{tabular}{lcc}
\hline & Fully Ambulatory & Not Fully Ambulatory \\
McGill Residents & 29 & 19 \\
Columbia Residents & 63 & 39 \\
Yule's $Q=0.02, X^{2}=0$ (not significant), $p<0.05$ & \\
\hline
\end{tabular}

However, recent hospitalization proved to be a significant variable, when the "community" group, the Project, was compared to each, of the Nursing Homes. Recent hospitalization was operationally defined as a hospital experience within one year. The Yule's $Q$ also shows some strength of relationship with the values with McGill Nursing Home resi- 
dents and Columbia Nursing Home residents as compared to the Project clients, as being 0.56 and 0.69 , respectively. When the two Nursing Homes were compared, no significant relationship was found. Therefore, it would seem that recent hospitalization is one of the few physical health factors that differentiate an institutionalized group; and a group of elderly persons receiving supportive services through a community delivery system. This relationship is seen in the following tables.

TABLE XIXa

A COMPARISON OF THE RELATIONSHIP OF RECENT HOSPITALIZATION AMONG INSTITUTIONALIZED PERSONS AND THE PROJECT CLIENTS

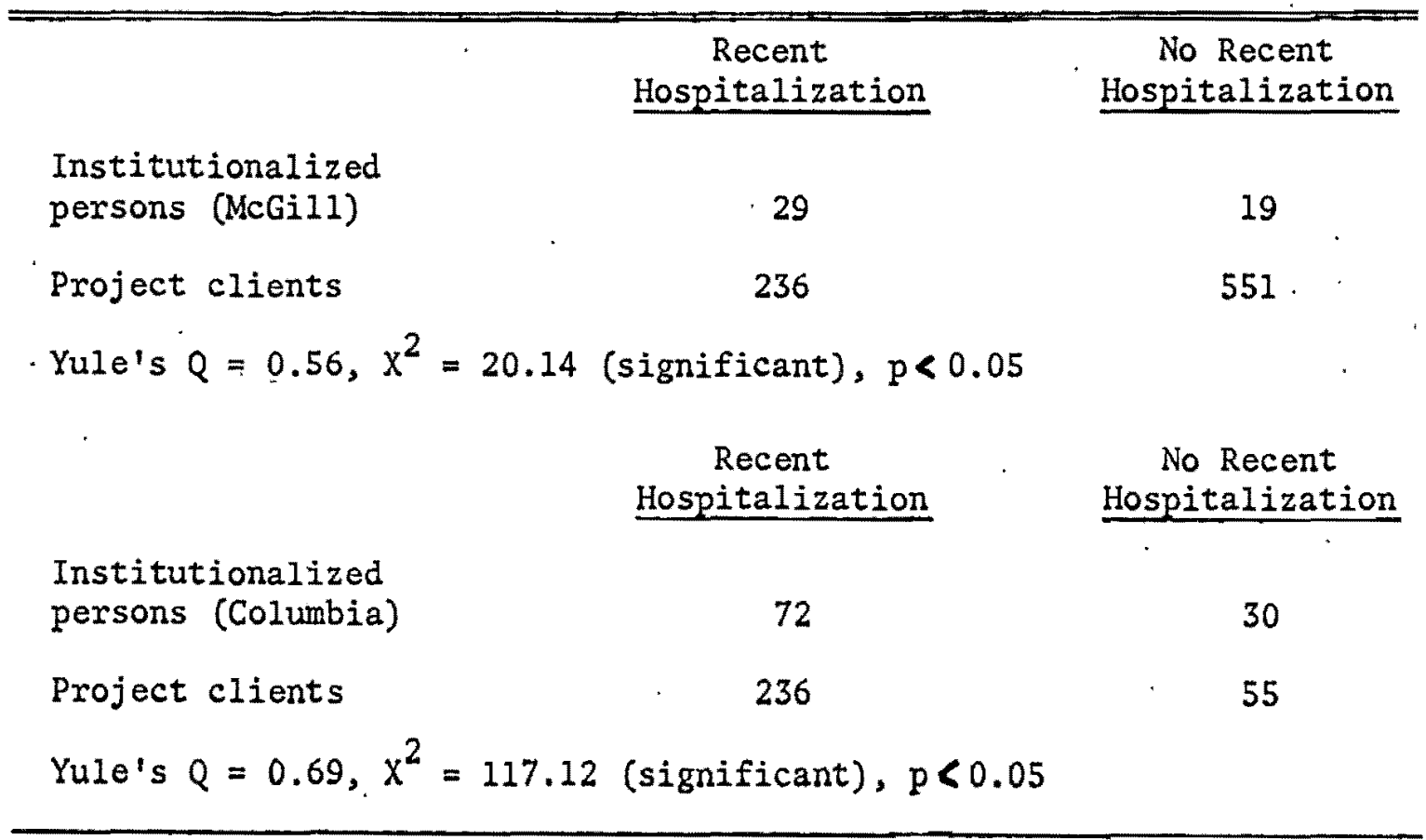


TABLE XIXb

A COMPARISON OF THE RELATIONSHIP OF RECENT HOSPITALIZATION
BETWEEN THE TWO NURSING HOMES

\begin{tabular}{|c|c|c|}
\hline & $\begin{array}{c}\text { Recent } \\
\text { Hospitalization } \\
\end{array}$ & $\begin{array}{c}\text { No Recent } \\
\text { Hospitalization }\end{array}$ \\
\hline McGill Residents & 29 & 19 \\
\hline Columbia Residents & 72 & 30 \\
\hline
\end{tabular}

\section{Mental Health}

The nursing home residents tended to have more severe mental health problems than the Project clients. This is in spite of the fact that almost half, $46 \%$, of the clients appeared to suffer at least moderate problems in the mental-emotional health domain. The most frequent complaint, "anxiousness," was cited by $22 \%$ of the clienț. However, the reality of being poor and alone, as are the majority of the clients, might indeed cause feelings of "anxiousness," as a normal reaction to their economic and social status. Only $3 \%$ were rated as having a severe mental health problem. Severe was defined as exploited by others, danger to self or others, conflict with community.

The mental health condition of the residents of McGill was assessed by their medical reports, and by asking the patients questions regarding their past and present mental-emotional state, and by an interviewer rating of the patients' condition. The interviewer rating showed $15 \%$ totally confused, $27 \%$ modexately so, and $57 \%$ oriented. Nineteen percent of the patients at McGill were diagnosed upon admission as suffering from a mental illness. These included cerebral arteriosclerosis with 


\section{CHAPTER IV}

\section{RESEARCH AND THEORY IMPLICATIONS}

\section{A. DISCUSSION OF RESEARCH FINDINGS}

The five variables that appeared to distinguish significantly the "institutionalized" groups from the "community" group were: (1) a. lack of social relationships with relatives, (2) a lack of social relationships with friends, (3) living alone, (4) birthplace, and (5) recent hospitalization. Each of these variables, with possible theory implications, will be discussed in turn.

This present study, although only a pilot study, has opened another insight into the possible recognition of those elderly individuals who are "at risk" of institutionalization. Elderly people who have little contact with relatives and especially friends may opt for an institutional health system. This supports the findings of Dr. Irving Rosow's study of 1964. Rosow's study was concerned primarily with the dimension of personal integration, group living, and friendship patterns, with special emphasis on the effects of residential density upon these. Results indicate that density is a significant factor in the provision of friendships, and that the working class person is more dependent upon friends within the neighborhood setting than is the middle class person. Apparent too in his study was that, with respect to help patterns, older people depend primarily upon other older people. ${ }^{35}$ If friendships between elderly persons are an important factor for "community" living, this leads 
back to the often-debated question, "Should age-segregated or ageintegrated housing be encouraged?" This study cannot answer this question, but does lead to the necessity for further research to help clarify this issue.

Living alone proved to be a significant factor differentiating the "community" approach to health care and the "institutional" approach. To maintain the independence desired by so many of the elderly, thought should be given to the planning of dwellings designed specifically to suit the elderly, which could be grouped in small numbers. This would also make it easier to supply home and personal services. Perhaps as is done in many of the European countries, a caretaker could oversee the wellbeing of the residents. This would ensure a certain amount of care and protection for the elderly person, and still maximize independent living .

Although foreign-born status was significant in the Nursing Home residents, it is thought that due to historical reasons and recent immigration laws, this variable might change in the future. Perhaps, though, in the future what should be looked at is the equality of health services to all American ethnic groups. It is a question if all American-born ethnic groups are served equally in health care systems, whether it be "community" care or "institutional" care. The White House Conference on Aging, 1971, held Special Concerns Sessions on The Elderly Among Minorities. These sessions included reports and recommendations from the Asian Americans, the Spanish-Speaking Elderly, the Aged Blacks, and the Elderly Indian. Perhaps consideration should be given to the following recommendation. The low percentage of other races, in both Nursing Home groups studied, may reflect inequality. 
The greater problem for black aged is not one of remaining without, but of getting into nursing homes. Thus, sufficient attention to reducing barriers preventing needed black admissions to nursing homes is urgently needed. 36

An examination of the health characteristics of the two aged groups in this present study, one receiving institutional care and the other receiving supportive services while living in the community, suggests that the institutional residents were not in fact substantially more impaired than the non-institutionalized group. This would imply that if a wider range of options was offered to the elderly, perhaps institutional care would not always be chosen. Misplacement of those needing health care services would then be reduced. Theoretically it appears that the different levels of intervention on the health care continuum should be distinctly different from each other. Consequently, those persons opting for services at the different levels of care should be distinctly different. If this were so, there would be synchronization between the needs of the individual and those services offered through each approach. However, this distinction does not seem to be very clear, as the difference between the two populations does not seem to be major. of the five significant differences, the major difference as far as the health care system is concerned is the incidence of recent hospitalization. Perhaps what is needed for an aging population is intervention techniques to be implemented prior to emergence of a crisis situation. It also appears that physicians and other professionals should be recruited into the on-going planning activities of Projects, such as the Community Project, so as to increase the utility of community services to the elderly hospital patients. Hence, in the event that complete recovery is not achieved by certain aged patients within a reasonable 
period of hospitalization, medical personnel can call upon the services of the community-based care system. Since these same elderly patients appear to have less contact with relatives and friends, and are more likely to live alone than those who avoid hospitalization, such outside intervention and guidance by medical personnel seems essential.

Returning to the assumptions enunciated by Jerome Kaplan, that--

1. There are alternatives [to Nursing Home care]

2. Nursing Home care is the "last step"

3. Independent home care is "better" for the aged American than nursing home care

4. People prefer to remain in their own homes under all conditions

5. Home care is "cheaper" than nursing home care

6. Many people do not have to be in nursing homes--

a number of comments based on this research would be appropriate. Although the general level of impairment, including disability and chronic illness, was similar, one cannot automatically assume that for many of these people there were alternatives to institutional care. Although supportive services through a community service system is generally. agreed upon to be the soundest approach, both economically and psychologically, for the individual, it is not always feasible. Nor can we legislate what is "better" for the aged person. Free "choice," even to choose an institutional form of care, must be given. The residents of McGill Nursing Home were asked whose idea it was to enter this home. Thirteen percent responded it was their own idea, and another $43 \%$ answered it was partly their own idea.

Nursing Home care was not regarded as the "last step" by many of these same residents, as $66 \%$ retained the ownership of their home and felt they could move back. However, considering the self-maintenance measures, cited earlier about this same group, it is evident that suppor- 
tive help would be needed to take the step to go back into their own homes.

The eight questions posed at the beginning of this research will now be the subject of discussion. These questions are:

1. Is the Nursing Home a specialized facility, rendering a necessary service to the aged?

2. Does there exist a great amount of pathology in the aged who seek institutional care?

3. Should institutional care be viewed as one needed program in a continuum of services for the elderly?

4. Is it possible that the individual components of a comprehensive service system do indeed permit community living as a realistic alternative to institutionalization?

5. Although the maintenance of independence is the philosophy behind a delivery system, is it possible that such a system might actually foster dependence even though it manifestly seeks independence--by becoming a "wa11-less" institution?

6. Is the population of elderly persons receiving services through community care system similar or dissimilar to the formally institutionalized populations?

7. Does residence in a total institution seem to produce effects similar to, or dissimilar from, the reception of services via a community care system?

8. Does this study validate the belief that the aged postpone treatment until the crisis stage, and thus over-rely on hospital care, the most expensive level of care?

For the $12 \%$ of the McGill residents, and the $21 \%$ of Columbia residents who require skilled nursing care, the Homes would certainly be seen as a specialized facility, rendering them a necessary service. It would seem that despite the host of services which are needed as alternatives to institutional care, there will come at some point a complex of services available only in an institution. However, as Louis Lowy has pointed out, gerontological research is needed to give direction to policy planners and decision makers as to: 
1. The nature of conditions which makes the use of an institution preferable to keeping older people in their own homes; and

2. The types of institutional services that are essential to meet the criteria of a healthful living arrangement for the older person. 37

Certainly at present, with the social conditions of the aged; the unsuitable housing, the inadequate income, the need of many to travel long distances and sit for hours in clinics to get medical services, isolation and loneliness are among the conditions which contribute to both mental and physical deterioration and undermine the ability to live independently. Thus for many elderly, the institution is a valid resource.

In answer to the second question, a great amount of pathology existed for both the institutional and non-institutional aged. As has been discussed previously, mental health status seemed to be healthier with less serious problems in the community group. A recent hospitalization experience differentiated the institutionalized. from the noninstitutionalized group. Since hospitalization is usually preceded by an acute attack, acute illness would be of higher incidence in the institutionalized aged.

In answer to the third enquiry, institutional care should be regarded as a needed program, but research is necessary to help delineate its functions and types of services peculiar to its system. A lack of emphasis has been given to rehabilitation of the elderly, and hence a thrust in this area is needed. Research of the kind currently conducted by the Community Project needs to be continued to help identify the individual components of a comprehensive service system which permit community living as a realistic alternative to institutionalization. 
Presently, according to Lowy, services for the elderly are classified in five major categories. These are:

1. Medically-oriented services;

2. Services to enhance a person's ability to participate in the activities of daily living such as homemaker services, food services;

3. Services to maintain social contact and participation which include friendly visiting, group services, day center programs;

4. Problem-solving and socially supportive services, e.g., counselling, information and referral, protective services; and

5. Financial assistance services. 38

Certainly these five areas should be available; however, knowledge is needed to know when and where to utilize them most effectively. The current working assumption is that older people would be maintained in their own homes as long as possible, with the availability of social and medical services to make this feasible. Institutionalization has been stigmatized, yet research findings concerning all of these five areas leave much to be desired. Cross-sectional studies have predominated, and there has been an absence of sound theoretical approach. As Louis Lowy cautions, "If we want to initiate, expand, and develop social services for older people, we need to know upon which kind of available theories and research findings we may draw that can provide us with guideposts for action." 39 The dearth of knowledge in this area of alter-native forms of services for the aged is classically summed up in the following words of Peter Townshend:

We need to know more about the alternatives and potential alternatives to institutional care. In what condition the chronic sick, the mentally ill, and the infirm aged safely live in homes of their own? What are the costs, not only economic, but in 
terms of emotional strain upon relatives, and neighbors, of administrative organization, and mental and physical health? How far is it practicable to take services to individuals rather than individuals to institutions? Only when we can answer such questions with more confidence will it be possible to decide the purpose and future role of the institution in society. We do not yet realize how difficult it is to meet some of the diverse psychological, social, occupational, and educational needs of individuals in institutions as we know and define them, or how 40 much more difficult it is to meet them there in the community. 40

This needed research would also give insight into the fourth question of interest and concern.

Question five posits the social psychological inquiry into whether a communty delivery system might foster dependence despite its manifest search and purpose for independence. This present research cannot answer this question, but its implications are worth pondering, and its possible reality should be researched. The sixth question has previously. been explicated in Chapter III. In order to answer question seven; a stricter methodological design is needed. A longitudinal study which assessed a population prior to entering an institution would permit a more precise determination of the amount and kind of influences which are produced by institutionalization. Since there is no knowledge available on the two nursing home groups prior to their institutionalization, any relationship found cannot be confused as a cause of institutionalization. It may be that individuals who apply to institutions are a unique sample with certain peculiarities from the beginning. Correlation cannot be interpreted as causation.

Question eight, which refers to the belief that the aged postpone treatment until the crisis stage, certainly seems to have been addressed, and insight received, by this research. Clearly the significant incidence of previous hospitalization before admittance into the nursing 
homes might indeed lead to: the conclusion that the elderly in these specific populations did indeed postpone treatment until the crisis stage. Thus the apparent over-reliance on hospital care might indeed be seen as perpetuating and accentuating the most expensive level of health care which is available.

\section{B. PROPOSED FURTHER RESEARCH}

The necessity of continued research into the effects of different delivery systems, and the types of people who rely on these systems, seems essential, if congruence between the needs of individuals and society is to be achieved. As a contribution to on-going research, the following research ideas and recommendations are offered.

The typology presented in Chapter I could be used as a basic tool for study and research. The first and perhaps the most important decision to be made is sampling procedures. To ensure initial comparability of groups, randomization of subjects would be the ideal procedure, since random allocation serves as a basis for making statistical inferences concerning whether observed differences among the groups are due to chance or intervention. However, since this procedure might receive criticism from an ethical point of view, closely matched samples of persons receiving services through a different mode of delivery, would be a necessity. Matching would include age, sex, marital status, demographic variables, education, occupation, and social and economic status. Thus matched samples from each of the five categories would be desirable. These categories are: Total Institution, Halfway House (e.g., retirement hote1), Community-Based Delivery System (such as Project ABLE, the Project used in this study), and Affiliate Program (e.g., a Day-Care 
Center), and a sample living in community with no tie to a system of supportive services (i.e., bar financial aid in the form of a pension or social security). In an attempt to dimensionalize, define, and measure institutional or non-institutional environment, the four aspects of Goffman's definition of a total institution could be adopted. These aspects are: Rational Plan, Scheduling, Batch Processes, and A11 Aspects of Life Controlled.

In this pilot study, which tried to account for the differences between aged individuals who are institutionalized to receive a supportive service or services, and those aged remaining in the community and receiving supportive services, the following variables seemed to be of importance: recent hospitalization, living alone, social contact with relatives, social contact with friends, and birthplace. Since these variables have been ascertained to be of possible significance, a stepwise linear regression might be an important approach to employ in the analysis of further research. The different mode of environment and delivery of system could be the dependent variables. Multiple regression analysis is a method used to predict a single dependent variable from any number of independent variables. By observing the square on the multiple correlation coefficients for predicting the dependent from the independent variables, it will inform the researcher of the proportion of total variance in the dependent variable which can be explained by all the independent variables operating together. The question of the strength of the partial association between the dependent and each of the independent variables could also be addressed by examining the partial correlation coefficients between the independent variables and the dependent variable, controlling on all other independent variables. 
It is thought that the five desired populations may indeed be difficult to find in one geographical area in the United States. Presently in the United States there is a lack of community support services to help maintain the aged patient in his own environment. However, in Western European countries this is not the case. For example, in England each local authority health service is required to supply the following supports which the aged utilize: chiropody service, meals on wheels, home help service, occupational therapy, recuperative holidays, residential homes for mental health, home nursing, health visiting, ambulance service, day centers and clubs, and residential accommodation. Even though such services vary in strength from community to community, the geriatric practitioner can rely on the support being basically available. ${ }^{41}$ Consequently, to locate different service delivery environments, the types of aged persons using the different service systems, and the effects on the aged persons, it would perhaps be necessary to research these areas of interest in a European setting first. Hopefully various alternatives to institutional care, such as offered in England, will soon be implemented in the United States, and then the research could be replicated in an American environment. 
CHAPTER V

POLICY RECOMMENDATIONS AND SPECULATIONS

The 1971 White House Conference on Aging Recommendations on the section concerning Facilities, Programs and Services urged that:

National policy should guarantee to all older persons real choices as to how they should spend their later years. Older persons should be enabled to maintain their independence and their usefulness at the highest possible levels . . . Action is needed in forging a national, social policy on protection of the older person's right and choices that will be reflected in provision of a wide range of facilities, programs, and services whether preventive, protective, rehabilitative, supportive or developmental in their forms. 42

"Independence" and its correlate "choice" are two noted aspirations of older people as a class in anticipating, planning for, and living their later years. As Dr. Wịlma Donahue, upon examining the results of some surveys dealing with housing preferences of elderly groups, stated, "The most salient fact emerging from those studies is the almost universal desire for continued independence in living arrangements." 43

The beginning for the fight to improve and enhance "independence" lies in the realm of income. Donald Kent saw as the major block to independent living for the aged to be inadequate income, and urges the fight for independence to begin there. He states:

Money alone will not guarantee independence; however poverty will almost guarantee its absence. It is very difficult for the person existing below the poverty line to feel that he has a measure of control over where he will live, where he will go, and the life style that he will follow. Economic independence is a prerequisite to social independence. Unfortunately one-quarter of our older people fall below the poverty line and another equally large group are so close to it that its chilly effects are felt. 
Poverty, alas, does not exist alone but usually brings with it a number of multiple hazards: limited education, poor housing, and poor health. There is almost a syndrome attendant with poverty and all of its aspects mitigate against independent living. ${ }^{44}$

In the area of personal health care expenses, the disproportionate burden of expenses to be shouldered by the elderly is quite evident. "In the fiscal year 1967, personal health care expenditures averaged $\$ 486$ per person 65 years of age and older, which was about 2-3/4 times the average for a younger person $(\$ 177) .45$ ]

Thus in the area of health care services, it is urged that much creativity must be fostered in the development of alternatives to total institutional care, in order to enhance the "independence," and to expand the areas of "choice" for the aged population. However, as'an incentive to this creativity must come federal and state support, through the allocation of funds. At present, there is money to pay for institutional care, but very little money to support community programs that offer the alternative of letting older persons live in their own homes. It is becoming clear, however, that far too large a proportion of the health care dollar is being spent in the United States in institutional care. Thus this research fully endorses the following remarks of the Special Senate Committee on Aging:

It is clear that far-reaching changes--including more options to States under Medicare--are required to reverse or reduce present over-dependence upon nursing homes and other institutions in which our elderly population is disproportionately represented . . . Steps should be taken to establish what should be the first line of defense for the older person: Resources that will enable him to stay at home instead of experiencing the trama of institutionalization . . A more flexible use of public assistance payments and the funds now available only for nursing home care through Medicaid would provide a sufficiently secure financial basis to encourage the emergence of personal care organizations of the type needed. 46 
Another area of care that must be addressed and supported by federal funds is the area of social maintenance services. It must be recognized that long-term care predominantly requires social maintenance rather than specificaliy medical types of services. Currently, Home Health Aides, employed by Medicare-certified agencies, are legislatively limited to medical care, and are unable to be responsive to the multiple social service needs of the individual or his family. Thus it is highly recommended that a public policy, geared at supplementing personal care services, as well as medical services, be encouraged, and that there be an increase of funds in this direction. Community living must also be rewarded, and not just institutional living. Perhaps. with this kind of incentive, decisions to institutionalize an aged person may not be forced on doctors, social workers, families, and friends.

The finding by this research, that recent hospitalization is a significant factor for entrance into a nursing home, has a number of ramifications for physicians and other medical personnel. Since to a large extent, physicians serve as gate-keepers into nursing homes, they must be led to know about, perceive the utility of, and recommend the utilization of a community-based service delivery system. The usage of such a system certainly will be increased and be recommended if the usual definitions of suitable reimbursible treatment under health insurance and Medicare/Medicaid be redefined to enable treatment from community home service agencies to be delivered at low cost or no cost to the elderly who need them.

Perhaps the whole concept of "hospitalization" has to be changed, so that entrance into a hospital by an aged person will not increase the likelihood of institutional care. Perhaps Peter Townshend's vision of 
the changing hospital scene might indeed be what is needed. He envisions the resolving of the dilemma of care for the aged as lying in two directions :

The first might be to restrict hospital provision to general "accident" or "acute" hospitals with highly specialized treatment wards and adjoining "recovery" and outpatient annexes, breaking down the present separation between "general," "chronic sick" and "mental hospitals." These would be for people staying for brief periods who require surgery and other forms of treatment which cannot be given in their own homes. The second means might be to gradually abandon most othex types of institutions, as we know them, by creating special types of housing and day clinics and by providing a much richer variety of home and welfare services. Those institutions that remain would have the purpose of assisting individuals through a transition from adversity or dependence to an independent home life. To me, such a policy seems to follow logically from a projection of the trends we are now witnessing in our social services. It would take a long time to achieve and would involve immense difficulties. But once we accept the principle that no advanced democratic society should deny the individual the right to a normal home and family life, it does not seem that any other course is open to us. 47

The movement to social services for older persons is gradually receiving recognition and implementation. As implementation is beginning, further policy implications are becoming evident with the concepts of "broker" and "market," which are now receiving attention.

Besides the claxity of goals and commitment to humanitarian values, the effective delivery of quality social services to older persons on a differential basis depends also, according to Lowy, on the available knowledge of how to bring dispensers and consumers of services together. ${ }^{48}$ This point of interest was evident in the 1973 Amendment to the older Americans Act, which incorporated a change of policy from the welfare model to the market model. As Byron Gold has stated:

Administration officials became convinced that the mechanism called for the services for the elderly market was a middle man, a broker, if you will. A broker makes a market; he brings buyers and sellers together. The function of this service broker, who was frankly described as an individual with highly 
developed entrepreneurial instincts, would be to use Federal dollárs:

to concentrate the demand of older persons for services;

to search out and, if need be, create sources of supply to meet the demand;

to control the quality and cost of services;

to assure that information about the availability of services reached all older persons in an area, not'just those who participate or who are mobile or are literate;

to assure that services are accessible and are packaged in a form which matches the mix of each individual older person's needs. 49

Thus it is evident that the Federal and State governments, as well as private agencies, are coming to assume the responsibility for, and conversely the individual aging person has come to demand, a broad range of community services and facilities. Hopefully before long there will exist congruence between the needs of the individual and the services offered.

Realistically, even ruling out the facet of ability to pay, few communities at present have as great a service capacity for in-home care as is available within institutions. Perhaps, then, a prime urgent need to be emphasized, in response to the original question of this study-"How does one best provide services needed by older persons?"--is to encourage changes in the atmosphere and character of the existing institutions by the introduction of a number of features of home and community 1ife. It is also recommended by this research that the stringent quality standards of Extended Care Facilities and Nursing Homes be enforced, especially those facilities which receive federal funding.

What the future will bring in services to the aged remains to be seen. It is believed that direction for the betterment of the elderly is available for policy makers and decision makers. It is the recommendation of this study that, no matter what mode or modes of service delivery systems are implemented, the overriding goal of all the recommendations 
of the 1971 White House Conference on Aging be the guiding force:

To assist the aging person to maintain his independence and to provide dignified protection and assistance for those unable to maintain full independence. 50 


\section{REFERENCES}

1. Clark Tibbitts, "Middle Age and Older People in American Society." Paper prepared for the Training Institute for Public Welfare Specialists in Aging (Cleveland, Ohio, June, 1965).

2. For further clarification of the problems of legal status, see Leonard Cain, "The Growing Importance of Legal Age in Determining the Status of the Elderly." Paper presented at the annual meeting of the Gerontological Society, San Juan, Puerto Rico, Dec. 20, 1972, and accepted, as revised, for publication in The Gerontologist, 1973.

3. Herman B. Brotman, The older Population: Some Facts We Should Know (Washington, D. C.: Administration on Aging, April, 1970).

4. Robert L. Wilson, Urban Living Qualities From the Vantage Point of the Elderly (Institute for Research in Social Science, University of North Carolina, 1960), p. 27.

5. Abraham Kostick, "A Day Care Program for the Physically and Emotionally Disabled," The Gerontologist, 12 (1972): 134-138.

6. Carter Osterbind (ed.), Independent Living for 01der people (Gainesville: University of Florida Press, 1972), p. ix.

7. Alvin Goldfarb, "Institutional Care of the Aged," in Behavior and Adaptation in Later Life, ed. by Ewald Busse and Eric Pfeiffer (Boston: Little, Brown and Co., 1969), pp. 289-321.

8. Talcott Parsons and Renee Fox, "I1lness, Therapy and the Modern Urban American Family," Journal of Social Issues, 8 (1962): 2-3, $31-44$.

9. Clark Edward Vincent, "The Family Health and Illness: Some Neglected Areas," Annals of the American Academy of Political and Social Science, 346 (March 1963): 109-116.

10. Odin W. Anderson and Ronald M. Anderson, "Patterns of Health Services," in Handbook of Medical Sociology, ed. by Howard Freeman, Sol Levine and Leo G. Reeder (Englewood Cliffs, N. J.: Prentice-Hall, Inc., 1972), p. 389 .

11. Jerome Kaplan, "Alternatives to Nursing Home Care: Fact or Fiction," The Gerontologist, 12 (1972): 114.

12. John E. O'Brien, "The Community Service System: Alternative to, or Alternative Form of, Institutional Care." Paper accepted for publication in The Gerontologist, 1973. 
13. "Health. Aspects of the Economics of Aging." Prepared by Advisory Committee for the Special Committee on Aging, United States Senate, July, 1969 (Washington, D. C.: U. S. Government Printing Office, 1969), p. 1 .

14. Ethel Shanas, "Health Care and Health Services for the Aged," The Gerontologist, 5 (1965): 240.

15. Sheldon Tobin, Jerome Hammerman, and Vicki Rector, "Preferred Disposition of Institutionalized Aged," The Gerontologist, 12 (1972): 129-133.

16. Helen Kistin and Robert Morris, "Alternatives to Institutional Care for the Elderly and Disabled," The Gerontologist, 12 (1972): 139-142.

17. Ibid.: 139.

18. Charles I. Schottland, The Social Security Program in the United States (New York: Appleton-Century-Crofts, 1970).

19. "Social Security Rulings," Cumulative Bulletin, 1971, SSR 71-1 to SSR 71-S7, U. S. Department of Health, Education and Welfare, Social Security Administration: 121.

20. Ibid.: 121 .

21. Morton Lieberman, "Institutionalization of the Aged: Effects on Behavior," Journal of Gerontology, 24 (1969): 330-341.

22. Ju-Shu Pan, "A Study of the Influences of Institutionalization on the Social Adjustment of old People," Journal of Gerontology, 3 (1948): $276-280$.

23. Ruth Laverty, "Nonresident Aid--Community Versus Institutional Care for. 01der People," Journal of Gerontology, 5 (1950): 370-375.

24. M. Pollack, et al., "Perceptions of Self in Institutionalized Aged Subjects: I Response Patterns to Mirror Reflections," Journal of Gerontology, 17 (1962): 405-409.

25. Ruth Bennet and Lucille Nahemov, "Institutional Totality and Criteria of Social Adjustment in Residences for the Aged," Journal of Social Issues, 21 (1965): 44-78.

26. Rodney M. Coe, "Self Conception and Institutionalization," in 0lder People and Their Social World, ed, by Arnold Rose and Warren Peterson (Philadelphia: F. A. Davis, 1965), pp. 225-243.

27. I. Gitlitz, "Morbidity and Mortality in 0ld Age," Journal of American

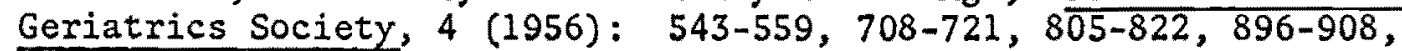
975-997 and 4 (1957): $32-48,299-305$. 
28. Nancy N. Anderson, "Effects of Institutionalization on Self-Esteem," Journal of Gerontology, 22 (1967): 313-318.

29. Morton Lieberman, Valencia Prock, and Sheldon Tobin, "Psychological Effects of Institutionalization," Journal of Gerontology, 23 (1968): $343-354$.

30. Ethel Shanas, Family Relationships of Older People, National Opinion Research Center, University of Chicago: Health Information Foundation, Series No. 20, October, 1961.

31. Don Martindale, American Society (Princeton, New Jersey: D. Van Nostrand Co., Inc., 1960), p. 200.

32. Joyce 0. Hertzlex, Social Institutions (Lincoln, Nebraska: University of Nebraska, 1946), pp. 4-5.

33. "Alternatives to Nursing Home Care: A Proposal." Paper prepared for use by the Special Committee on Aging, by Staff Specialists at the Levinson Gerontological Policy Institute, Brandeis University, Waltham, Massachusetts, October, 1971 (Washington, D. C.: U. S. Government Printing Office, 1971).

34. Erving Goffman, Asylums (New York: Doubleday and Co., 1961), p. 6.

35. Irving Rosow, Social Integration of the Aged (New York: The Free Press, 1967).

36. Toward a National Policy on Aging. Proceedings of the 1971 White House Conference on Aging, Nov. 28-Dec. 2, Vo1. II (Washington, D. C.), p. 184 .

37. Louis Lowy, "The Role of Social Gerontology in the Development of Social Services for Older People," in Research Planning and Action for the Elderly, ed. by Donald Kent, Sylvia Sherwood, and Robert Kastenbaum (New York: Behavioral Publications Inc., 1972), p. 23.

38. Ibid., pp. 22-23.

39. Lowy, "The Role of Social Gerontology in the Development of Social Services for Older People," op. cit.

40. Peter Townshend, "The Purpose of an Institution," in Social and Psychological Aspects of Aging, ed. by Clark Tibbitts and Wilma Donahue (New York: Columbia University Press, 1962), p. 395.

41. Dr. Lionel Cosin, Prepared Statement at Hearings before the Subcommittee on Long-Term Care of the Special Committee on Aging, United States Senate, Ninety-Second Congress, First Session, June 15, 1971 , p. 1402 .

42. Toward a National Policy on Aging, op. cit., p. 184. 
43. Wilma Donahue (ed.), "Where and How 01d People Wish to Live," in. Housing the Aged (Ann Arbor, Michigan: University of Michigan, 1954), p. 27.

44. Donald Kent, "Maintaining Independent Living in Contemporaxy Society," in Independent Living for Older People, ed. by Carter C. Osterbind (Gainesville: University of Florida Press, 1972), pp. 1718 .

45. Dorothy Rice, Arne Anderson, and Barbara S. Cooper, "Personal Health Care Expenditures of the Aged and Non-Aged," Social Security Bulletin, Table 2 (August 1968): 21.

46. "Alternatives to Nursing Home Care: A Proposal," op. cit., p.'iii, p. 7 .

47. Peter Townshend, "The Purpose of the Institution," op. cit., pp. 355356.

48. Lowy, "The Role of Social Gerontology in the Development of Social Services for Older People, op. cit., p. 29.

49. Byron Gold, "New Concepts of Service Delivery to the Aged." Paper read at the American Society of Public Administration Conference, Los Angeles, California, April 3, 1973.

50. Arthur S. Fleming, Foreword to Toward a National Policy on Aging, 1971 White House Conference on Aging, Final Report, Vol. I, Nov. 28Dec. 2 (Washington, D. C.), p. vii. 


\section{BIBLIOGRAPHY}

Anderson, Nancy N. "Effects of Institutionalization on Self-Esteem." Journal of Gerontology, Vol. 23 (1967): 313-318.

- "Institutionalization, Interaction and Self-Conception in Aging." In Rose, Arnold and Warren Peterson (eds.), 0lder People and Their Social World. Philadelphia: F. A. Davis, $\overline{1965,}$ pp. 245-257.

Anderson, Odin and Ronald H. Anderson. "Patterns of Health Service." In Freeman, Howard, Levine, Sol and Leo G. Reeder (eds.), The Handbook of Medical Sociology. Englewood Cliffs, New Jersey: Prentice-Hall, Inc., 1972.

Bennet, Ruth and Lucille Nahemov. "Institutional Totality and Criteria of Social Adjustment in Residents for the Aged." Journal of Social Issues, Vol. 21 (1965): 44-78.

Brody, Elaine and Berton Gummer. "Aged Applicants and Non-Applicants to a Voluntary Home: An Exploratory Comparison." The Gerontologist, Vo1. 7 (1967): 234-244.

Brotman, Herman. The Older Population: Some Facts We Should Know. U. S. Department of Health, Education and Welfare, S.R.S.-AoA-164, 1971.

Cain, Leonard. "The Growing Importance of Legal Age in Determining the Status of the Elderly." Paper presented at the annual meeting of the Gerontological Society, San Juan, Puerto Rico, Dec. 20, 1972, and accepted as revised for publication in The Gerontologist, 1973.

Campbe11, Donald T. and Julia C. Stanley. Experimental and Quasi-Experimental Design for Research. Chicago: Rand McNally, 1963.

Donahue, Wilma. Housing the Aging. Ann Arbor, Michigan: University of Michigan Press, 1954.

Gitlitz, I. "Morbidity and Mortality in 01d Age." Journal of American Geriatrics Society, Vol. 4 (1956): 543-559, 708-721, 805-822, 896$908,975-997$ and Vo1. 5 (1957): 32-48, 299-305.

Goffman, Erving. Asylums. New York: Doubleday, 1961.

Gold, Byron. "New Concepts of Service Delivery to the Aged." Paper presented at the American Society of Public Administration Conference, Los Angeles, California, April 3, 1973. 
Goldfarb, Alvin. "Institutional Care of the Aged." In Busse, Ewald and Eric Pfeiffer (eds.), Behavior and Adaptation in Later Life. Boston: Little, Brown, and Co., 1969, pp. 289-321.

Hertzler, Joyce. Social Institutions. Lincoln, Nebraska: University of Nebraska, 1946.

Kahana, Eva. "Emerging Issues in Institutional Services for the Aged." The Gerontologist, Vol. 11 (1971): 51-59.

Kaplan, Jerome. "Alternatives to Institutional Care for the Elderly and Disabled." The Gorontologist, Vol. 12 (1972): 114.

Kent, Donald, Sherwood, Sylvia and Robert Kastenbaum. Research Planning and Action for the Elderly. New York: Behavioral Publications, 1972 .

Kistin, Helen and Robert Morris. "Alternatives to Institutional Care for the Elderly and Disabled." The Gerontologist, Vol. 12 (1972): 139142 .

Kostick, Abraham. "A Day Care Program for the Physically and Emotionally Disabled." The Gerontologist, Vol. 12 (1972): 134-138.

Laverty, Ruth. "Nonresident Aid--Community Versus Institutional Care for older People." Journal of Gerontology, Vol. 5 (1950): 370-375.

Lieberman, Morton. "Institutionalization of the Aged: Effects on Behavior." Journal of Gerontology, Vol. 24 (1969): 330-341.

Lieberman, Morton, Prock, Valencia and Sheldon Tobin. "Psychological Effects on Institutionalization." Journal of Gerontology, Vol. 23 (1968): 343-354.

Lissitz, Samuel. "Theoretical Conceptions of Institutionalization and Community Care of the Aged." The Gerontologist, Vol. 10 (1970): $298-304$.

Lowy, Louis. "The Role of Social Gerontology in the Development of Social Services for Older People." In Kent, Donald, Sherwood, Sylvia and Robert Kastenbaum (eds.), Research Planning and Action for the Elderly. New York: Behavioral Publications, Inc., 1972.

Martindale, Don. American Society. New Jersey: D. Van Nostrand Co., Inc., 1960.

O'Brien, John E. "The Community Service System: Alternative to or Alternative Form of Institutional Care?" Paper accepted as revised for publication in The Gerontologist, 1973.

Osterbind, Carter (ed.). Independent Living for Older People. Gainesville: University of Florida Press, 1972. 
Pan, Ju-Schu. "Social Adjustment of Aged People." Sociology and Sociological Research, Vol. 33 (1949): 424-430.

"Personal Adjustment of 01d People." Sociology and Sociological Research, Vol. 35 (1950); 3-11.

- "A Comparison of Factors in the Personal Adjustment of $01 d$ People in the Protestant Church Homes for the Aged and O1d People Living Outside of Institutions." Journal of Social Psychology, Vol. 35 (1952): 195-203.

Parsons, Talcott and Renee Fox. "I1lness, Therapy and the Modern American Family." Journal of Social Issues, Vol. 8 (1952): 2-3, 31-44.

Pollack, M., Karp, E., Kahn, R. L. and A. I. Golfarb. "Perceptions of Self in Institutionalized Aged Subjects: I Response Patterns to Mirror Reflection." Journal of Gerontology, Vo1. 17 (1962): 405409 .

Rice, Dorothy, Anderson, Arne and Barbara S. Cooper. "Personal Health Care Expenditures of the Aged and Non-Aged." Social Security Bulletin (August 1968).

Rosow, Irving. Social Integration of the Aged. New York: The Free Press, 1967.

Schottland, Charles I. The Social Security Program in the United States. New York: Appleton-Century-Crofts, 1970.

Scott, Frances. "Factors in the Personal Adjustment of Institutionalized and Non-Institutionalized Aged." American Sociological Review, Vo1. 20 (1955): 538-546.

Shanas, Ethel. Family Relationships of O1der People. National Opinion Research Center, University of Chicago: Health Information Foundation, Series No. 20 (October 1961).

\begin{tabular}{l} 
Gerontologist, Vol. 5 (1965): 240. \\
\hline
\end{tabular}

Tibbitts, Clark and Wilma Donahue. Social and Psychological Aspects of Aging. New York: Columbia University Press, 1962.

Tobin, Sheldon, Hammerman, Jerome and Vicki Rector. "Preferred Disposition of Institutionalized Aged." The Gerontologist, Vol 12 (1972): 129-133.

Toward a National Policy on Aging. Proceedings of the 1971 White House Conference on Aging, Washington, D. C., Nov. 28-Dec. 2.

Townshend, Peter. "The Purpose of an Institution." In Tibbitts, Clark and Wilma Donahue (eds.), Social and Psychological Aspects on Aging. New York: Columbia University Press, 1962. 
- The Last Refuge. London: Routledge and Kegan Paui,

1962.

Townshend, Clair. 01d Age: The Last Segregation. New York: Bantam Books, 1971.

Tuckman, J. and Irving Lorge. "The Effect of Institutionalization on Attitudes Towards 0ld People." Journal of Abnormal and Social Psychology, Vol. 47 (1952): $337-344$.

- "The Attitudes of the Aged Towards the Older Worker: for Institutionalized and Non-Institutionalized Aged." The Journal of Gerontology, Vol. 7 (1952): 559-565.

Vincent, Clark Edward. "The Family Health and Illness: Some Neglected Areas." Annals of the American Academy of Political and Social. Science, Vol. 346 (March 1963): 109-116.

Wilson, Robert L. Urban Living Qualities from the Vantage Point of the Elderly. Institute for Research in Social Science, University of North Carolina, 1960.

\section{Government Publications}

"Alternatives to Nursing Home Care: A Proposal." A paper prepared for use by the Special Committee on Aging, by Staff Specialists at the Levinson Gerontological Policy Institute, Brandeis University, Waltham, Massachusetts, October 1971, Washington, D. C.: U.S. Government Printing Office, 1971.

Cosin, Dr. Lionel. Prepared Statement at Hearings before the Subcommittee on Long-Term Care of the Specialist Committee on Aging, United States Senate, Ninety-Second Congress, First Session, June 15, 1971.

"Health Aspects of the Economics of Aging." Prepared by an Advisory Committee for the Special Comnittee on Aging, United States Senate, July 1969, Washington, D. C.: U. S. Government Printing Office, 1969.

"Social Security Rulings." Cumulative Bulletin, 1971, SSR 71-1 to SSR 71S7, U. S. Department of Health, Education and Welfare, Social Security Administration. 
APPENDIX A

NURSING HOME STUDY

\section{INSTRUCTIONS TO INTERVIEWERS}

This interview is to be conducted using a sample of the patients in each nursing home who:

1) Are over 65 years of age,

2) Have been residents of the home for less than two years, and

3) Did not enter this nursing home directly from another nursing home.

Please fill out the information that is requested as fully as possible. The data for the first page should be taken from the record, if available. The rest of the interview is to be conducted as an informal questioning of the resident. Please place X's in the appropriate places, and comments on the designated lines. Please use red pen to make coding easier. Do not ask questions if answers have already been received in previous questions. Do not ask a question that is inappropriate to a particular person; $i . e .$, if the patient has no children, omit all questions on visiting with children. Put $\mathrm{n} / \mathrm{a}$ (not applicable) in space provided for the answer.

In cases where the person to be interviewed is confused, attempt to. record as much information as is given, and make a note as to the extent of the communication incapacity at the end of this form.

Thank you! 
NURSING HOME STUDY

PERSONAL DATA

I.D. Number

Census Tract

Zip Code

Soc. Sec. No.

Year of Birth

Place of Birth

Religion

Sex: Male Female

Race: Caucasian Other

Last grade. of school
(Codes)

Institution

Address

Date of Admittance

Physician

Physician location

Marital Status

Married Divorced

Spouse here Never

Spouse in

Community Married Widowed

Separated

\section{INSTITUTIONAL HISTORY}

Has this patient been in any other institution? Yes No IF YES, for what reasons

How many months has the patient been in this institution What services does the patient need?

Home for the Aged Occupational Therapy

Physical Therapy Semi-Skilled Nursing

Skilled Nursing Other

Recorded Reason for Admission

Medical Information 
ECONOMIC DATA

(Codes)

Expense per month spent on:

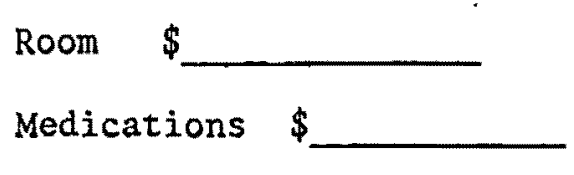

Discretionary Income per month (after room and medications)

$\begin{array}{lll}\$ \quad 0-49 & \$ 150-199 & \$ 300-399 \\
\$ 50-99 & \$ 200-249 & \$ 400-699 \\
\$ 100-149 & \$ 250-299\end{array}-$\begin{tabular}{ll}
$\$ 700+$ \\
\hline
\end{tabular}


LETTER TO PARTICIPANTS IN NURSING HOME STUDY

THE PORTLAND STATE UNIVERSITY, INSTITUTE ON AGING IS CONDUCTING THIS STUDY OF NURSING HOME RESIDENTS IN THE HOPE OF BEING BETTER ABLE TO SERVE BOTH RESIDENTS AND ELDERLY PEOPLE WHO LIVE IN THE COMMUNITY : BY TELLING US ABOUT THE PROCESS OF LEAVING YOUR COMMUNITY HOME AND MOVING TO THIS NEW LOCATION, YOU WILL HELP US IN OUR WORK TO OFFER SERVICES IN THE COMMUNITY AND IN THE NURSING HOME THAT ARE APPROPRIATE TO THE NEEDS OF THE PEOPLE.

THE STAFF OF THIS NURSING HOME HAS BEEN VERY COOPERATIVE WITH OUR EFFORTS IN THIS STUDY, AND THEY ARE ANXIOUS FOR YOU TO GIVE US AS MUCH INFORMATION AS POSSIBLE, SINCE THIS WILL ALSO HELP THEM TO SERVE YOU. ALL OF THE INFORMATION THAT YOU GIVE US WILL BE KEPT IN COMPLETE CONFIDENCE. YOUR NAME DOES NOT EVEN GO ON THE INTERVIEW FORM. AFTER WE HAVE COMPLETED INTERVIEWING RESIDENTS OF THIS NURSING HOME, WE WILL POOL THE INFORMATION INTO A REPORT DESCRIBING THE FEELINGS OF THE PEOPLE WHO LIVE HERE.

WE APPRECIATE YOUR COOPERATION VERY MUCH. THANK YOU. 
I. ADMISSION INFORMATION

1. First of all, I'd like to find out what was your reason for coming here?

2. Did you come here directly from your home, from a temporary stay with a relative, or from the hospital?

1. home

2. temp. situation

3. hospital

Were you covered by Medicare?

Had your coverage expired?

3. Was it your own idea to move to a nursing home?

1. yes

2. partiy

3. no

IF partly, or NO, was it suggested by

1. your doctor

2. your spouse

3. your children

4. a social agency

5. other

II. PHYSICAL CONDITION *

1. Would you say that when you came here your health was

1. good

2. fair

3. poor

2. Is it better, the same, or worse now than when you arrived?

1. better

2. the same

3. worse

Why?

III. COMMUNITY RESIDENCE

I would like to ask you a few questions about the place you lived $\because$ before you came here.

1. Were you living alone or with other people?

1. living alone

2. living with others 
COMMUNITY RESIDENCE (con't $)$

IF with others, who were they?

1. spouse

2. children

3. other relatives

4. non-relatives

Then there were people living with you?

2. Were you living in:

1. a house

2. an apartment

3. a rooming house

3. Did you own the residence, did a relative own it or did you rent it?
1. owned
2. relative owned
3. rented

4. I would like to learn something about your residence. Was it comfortable? Why?

5. Did it have modern conveniences, like a stove?

1. stove

2. refrigerator

3. bath

4. telephone

6. If you wanted to move back, is that place still available? 1. Yes 2. No

If not, why not?

IV. SELF CARE LIMITATIONS

1. I would like to find out from you what difficulties you had taking care of yourself when you lived at home. First, I will read some household tasks and I would like you to tell me if you could do them alone, or with some help, or not at all. Also tell me if any of these abilities to take care of yourself have changed since coming here. (Record + for positive changes, 0 for no change, and - for negative changes, in the change column below.) 


Alone $\begin{aligned} & \text { With Not } \\ & \text { Help at All (Code) }\end{aligned}$ (t,0,-) $\begin{array}{r}\text { Change } \\ (\text { Codes }+=1 \\ 0=2,-=3)\end{array}$
a. Shopping
b. Laundry
$1 \quad 2 \quad 3$
c. Cleaning
d. Cooking
$1 \cdot 2 \quad 3$
$1 \quad 2 \quad 3$
2. In taking care of yourself, could you:
a. Feed yourself
b. Get in and out of bed
c. Go to the toilet
d. Dress yourself
e. Bathe yourself
f. Follow doctor's orders:
$\begin{array}{llll}\text { about medicine } & 1 & 2 & 3\end{array}$
$\begin{array}{llll}\text { about exercise } & 1 & 2 & 3\end{array}$ $1 \quad 2 \quad 3$
$\begin{array}{rll}1 & 2 & 3\end{array}$
123
123
123

3. In your ability to move around, could you:

a. Move about in your home

b. Go out of the house

c. Use Public

Transportation

$\begin{array}{lll}1 & 2 & 3 \\ 1 & 2 & 3 \\ 1 & 2 & 3\end{array}$

V. SOCIAL SITUATION

1. Sometimes there are changes in a person's social situation which prompt them to leave their home. Prior to admission, were there any changes in your home or family life which caused you to come here?

a. Did something cause you to move out of your home?

b. Did a friend or relative who took care of you pass away? Yes_ No___ or

c. Were there any other events that made life unpleasant? Describe

2. Now I would like to learn about whom you visited with and what kinds of things you did when you were in the community.

a. How many times a month did you see your children? times/month

b. How often did you see other relatives? times/month

c. How often did you see your friends? times/month 


\section{SOCIAL SITUATION (con't)}

d. Did you participate in any church groups?

How often

e. Hobby clubs

f. Retirement clubs

g. Other social groups

How often
How often
How often

3. Considering all of the types of contact that you had with people during the year before you came here, would you say that you had:

a. Too many contacts with people

b. About as many contacts as you would have liked

c. Not as many contacts as you would have liked

4. Generally then would you say that you felt lonely:

a. Almost none of the time

b. Occasiona11y

c. Most of the time

5. Now we would like to know something about the social contact you have here. In a group residence like this, the pattern of seeing other people is different than it was at home. Since you have been here:

a. How many times per month do you see your children? times/month

b. How often do you see your spouse (if he/she does not live here)? times/month

c. How often do you see friends who live here? times/month

d. How often do you see relatives? times/month

e. How often do you visit with other friends. times/month

f. How often do you participate in social groups here? times/month

g. How often do you participate in social groups in the community? times/month

6. Considering all of the types of contacts that you have had since you have been here, would you say that you have had:

a. too many contacts with people

b. about as many contacts as you like

c. not as much contact as you would like

7. Living here, do you find yourself feeling lonely?

a. almost none of the time

b. occasionally

c. most of the time 


\section{SOCIAL SITUATION (con't)}

8. We would like to know how you feel about living here.

$\longrightarrow$

Specifically:

$\begin{array}{llccccc} & \begin{array}{c}\text { Very } \\ \text { Much }\end{array} & \text { Like } & \text { OK } & \text { Dislike } \\ \text { a. Do you like the activities } & 1 & 2 & 3 & 4 \\ \text { b. Do you like the food } & 1 & 2 & 3 & 4 \\ \text { c. Do you like your room } & 1 & 2 & 3 & 4 \\ \text { d. Do you like the care you get } & 1 & 2 & 3 & 4 \\ \text { e. Do you like the location of } \\ \text { this home }\end{array}$

What would you change about this place if you wished to improve it for yourself and for others?

VI. EMOTIONAL CONDITION

1. Sometimes there are other reasons which cause people to leave their home. Thinking back to when you were living at home, do you remember any of the problems that $I$ am going to read to you? Also, now that you are here, do you feel that there has been any change in these problems? (Record + for positive change, 0 for no change, and - for negative change, in the Change column below.)

YES NO Cd Code Change Cd Code
a. Being afraid for no reason
12
$(+, 0,-)$
b. Being easily annoyed and irritated
$\begin{array}{ll}1 & 2 \\ 1 & 2\end{array}$
c. Having trouble concentrating 12
d. Having trouble remembering past events
12
e. Having trouble with your nerves
f. Any other problems
12
12

VII. CONCLUDING COMMENTS Please tell us if there are any aspects of your life in the community, or things that prompted your decision to come here that we have not covered. 
INTERVIEWER RATING

Please indicate a rating for the Mental/Emotional Condition of the person just interviewed:

Total

No Problem Moderate Problem Incapacity

Confused Uncooperative Depressed

1

1

1

Non-communicative

1

2

3

3

3

2

2 


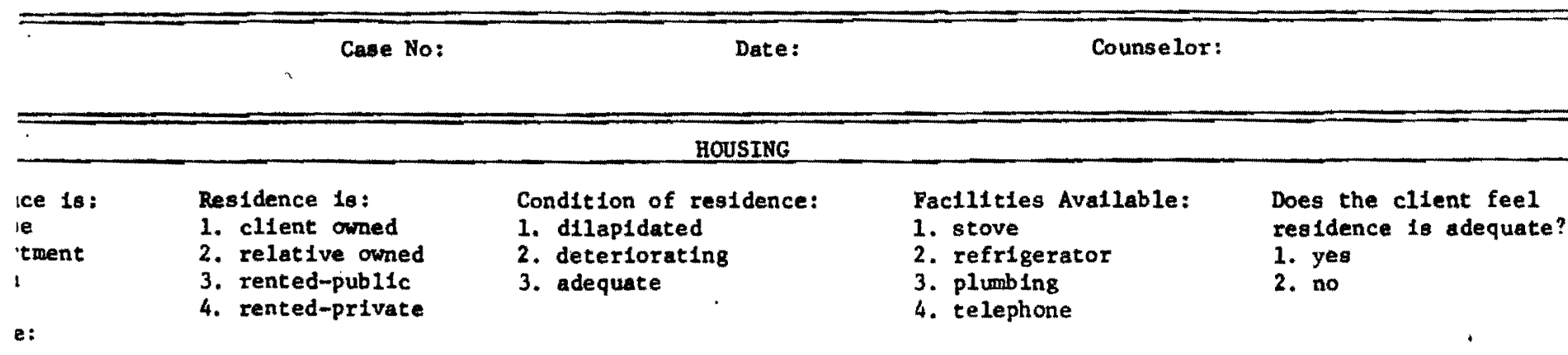

\begin{tabular}{|c|c|c|c|c|}
\hline \multicolumn{5}{|c|}{ HEALTH } \\
\hline $\begin{array}{l}\text { Problems? } \\
\text { lppled/amputee } \\
\text { ronic 111ness } \\
\text { gctures } \\
\text { lers }\end{array}$ & $\begin{array}{l}\text { Any impalrments? } \\
\text { 1. olght } \\
\text { 2. hearing } \\
\text { 3. apeech } \\
\text { 4. chewing }\end{array}$ & $\begin{array}{l}\text { Mobility restricted? } \\
\text { 1. tires easily } \\
\text { 2. cem1-ambulatory } \\
\text { 3. hombound } \\
\text { 4. bedr1dden }\end{array}$ & $\begin{array}{l}\text { Special aids? } \\
\text { 1. wheelchelr } \\
\text { 2. cane/crutches } \\
\text { 3. hearing ald }\end{array}$ & $\begin{array}{l}\text { Does the client foel that } \\
\text { his health prevents him } \\
\text { from dolng many thinge? } \\
\text { 1. yes } \\
2 \text {. no }\end{array}$ \\
\hline
\end{tabular}

Ibe:

\begin{tabular}{l|l|l|l|}
\hline $\begin{array}{l}\text { visit to doctor } \\
\text { months ago. }\end{array}$ & If hospltalized In past year, why? & \multicolumn{2}{|c|}{ Describe Known Admissions } \\
\hline $\begin{array}{l}\text { visit to dentist } \\
\text { monchs ago. }\end{array}$ & & Nursing Home & \\
\hline
\end{tabular}

EOONOMIC

.y Household Income:

Income Source (Give percent for each source - 100\% total)

lersons supported on this incowe:

11 Sec. No.

1. earnings

2. social security 3. welfare
4. other $\%$ 7 specify:

ire Case No.

SOCIAL CONTACT

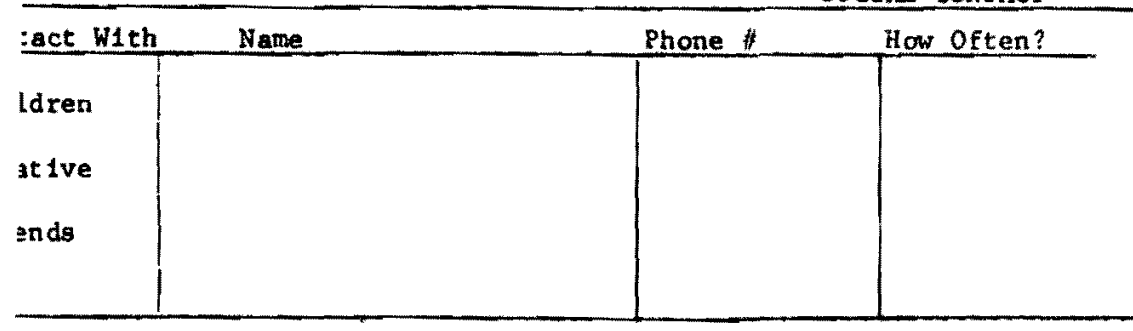

La1 Problema?

recent 108 of spouse

recent loss of relatives or close friends

. 0 relatives in county aree

to friends in nelghborhood
Social Groups How often?

ents: 
CURREAT SOCIAL SERYICE

zcy (used within past year)

Type of Service

Contect Person

Coimente:

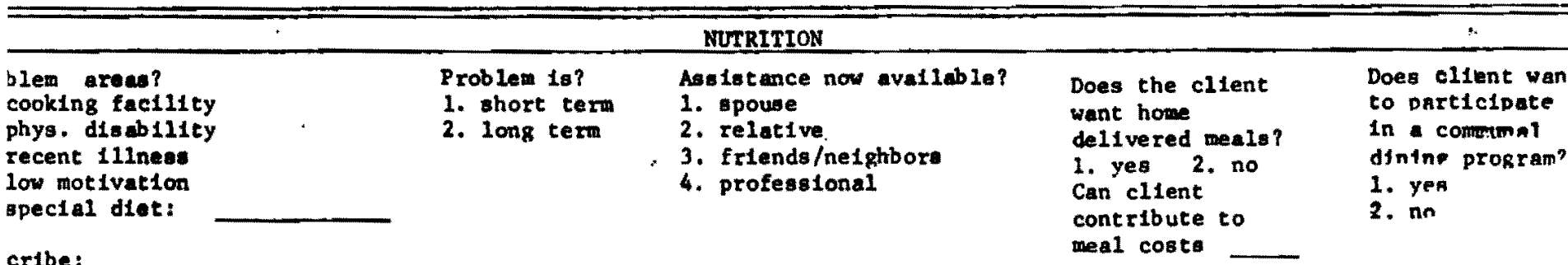

cribe:

\section{TRANSPORTATION}

\begin{tabular}{|c|c|c|c|c|c|}
\hline $\begin{array}{l}\text { ds assistan } \\
\text { frlends } \\
\text { relatives } \\
\text { church } \\
\text { otore }\end{array}$ & $\begin{array}{l}\text { ce to visit? } \\
\text { 5. medical facility } \\
\text { 6. comanunal dining } \\
\text { 7. bank }\end{array}$ & $\begin{array}{l}\text { Types now being } \\
\text { 1. own auto } \\
\text { 2. other's auto } \\
\text { 3. taxi }\end{array}$ & $\begin{array}{l}\text { used } \\
\text { 4. trans. program } \\
\text { 5. public trans. } \\
\text { 6. walking }\end{array}$ & $\begin{array}{l}\text { Ass lotance now avallable? } \\
\text { 1. epouse } \\
\text { 2. relative } \\
\text { 3. friends/ne1ghbors } \\
\text { 4. profess Ional }\end{array}$ & $\begin{array}{l}\text { Does client want } \\
\text { transportation } \\
\text { assistance? } \\
\text { 1. yea } \\
2 \text {. no }\end{array}$ \\
\hline
\end{tabular}

cribe :

\section{HOME HELP}

\section{blem areas?}

heavy housekeepling 5. personal care

light housekeep1ng 6. health/medication

meal preparation

shoppling

assist ance

7. howe repal:
Assistance now avallable?

1. spouse

2. relat Ives

3. frlend/nelghbor

4. professional
Would client accept home

help assistance?

1. yes

2. no

cribe:

LEGAL.

blem areas?

consumer 3. Eam1ly

Past use of lawyer?

4. personal 6. property mgment.

7. criminal
Who?

When?
Does the client want

to talk with lawyer?

1. yes

2. no
Recommend contact by:

1. phone

2. office visit

3. home visit

Icribe:

llem a reas?

al Health

inxious 4. depressed 7. exploited by others

zonfused 5 . frightened 8 , danger to self/others

iostile 6. forgetful 9. conflict with comminity
Phystcal Health

1. medications

2. chronic 111 ness

3. acute 11 Iness
Is the client adequately handling his situation?

stibe: 
INTAKE FORM B

\section{IDENT I FICAIION}

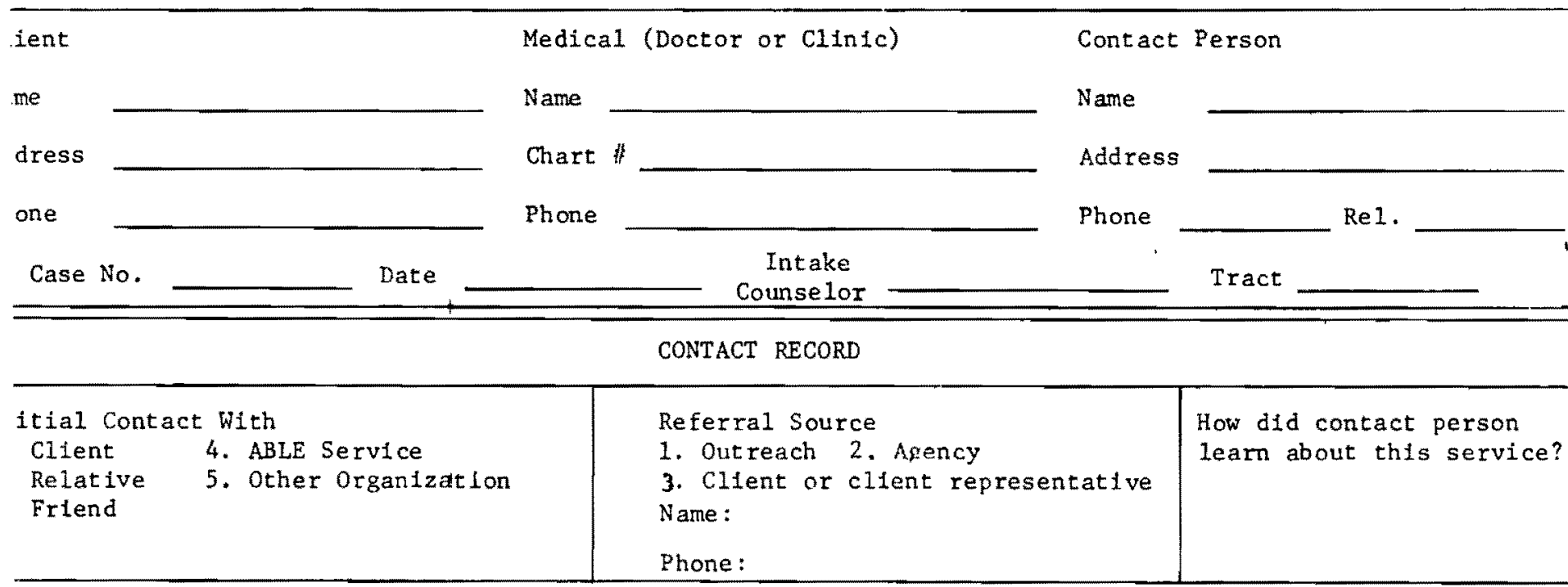

oblems Presented by the Client Phys. H1th. 4. Homemakers Mental HIth. 5. Nutri/meals Socla1 Serv. 6. Legal

7. Trans.

Describe:

8. Econ/Hsing

9. Gen. Inform

Referred: Where?
$\begin{array}{ll}\text { LE Services } & \text { 4. Homemaker } \\ \text { C/R } & \text { 5. Nutrition } \\ \text { Prot. Serv. } & \text { 6. Trans. } \\ \text { Legai } & \text { 6. Trat }\end{array}$

N-ABLE Services:
If Not Referred: Why?

1. Appropriate services not aval1.

2. Referral unnecessary (info. prov.)

3. Request for service withdrawn

4. No current need for services

5. No interview

Specify:
Central office Review

\section{PERSONAL DATA}

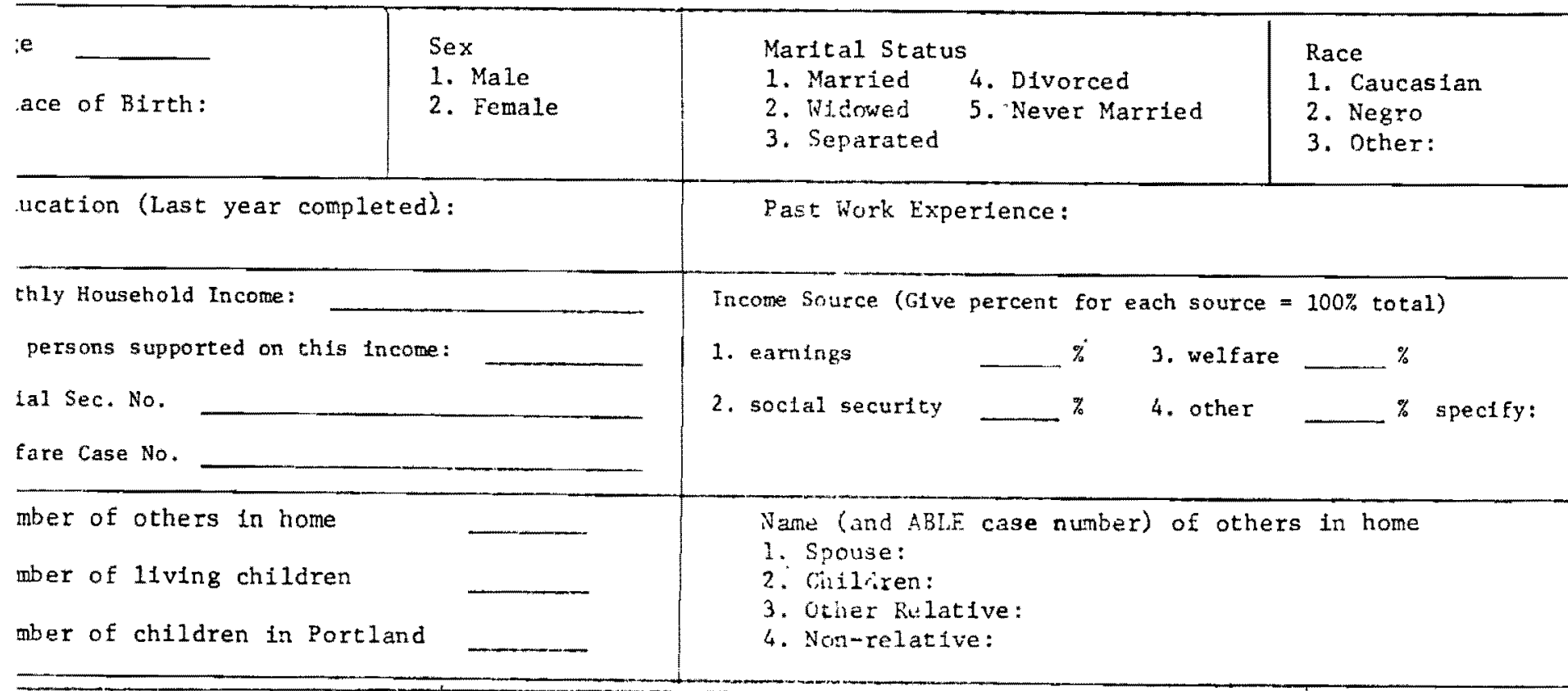

